\title{
Optimisation of a sustainable manufacturing system design using the multi- objective approach
}

\author{
(Reda Nujoom, Corresponding author), Qian Wang, and Ahmed Mohammed \\ School of Engineering, University of Portsmouth \\ Portsmouth, UK \\ Reda.Nujoom@port.ac.uk
}

8831 Word

\section{The main contributions of this research}

1) The concept of lean methods does not include environmental considerations in terms of such as energy consumption and $\mathrm{CO}_{2}$ (carbon dioxide) emissions, which are also important factors today for developing a sustainable manufacturing system. This research addresses these issues involved in modelling a sustainable manufacturing system allowing an evaluation in energy consumption and $\mathrm{CO}_{2}$ emissions against the total cost using the multi-objective approach. This a novel approach proposed in this study which has not explored in the current literature.

2) This research presents a development of a multi-objective model of a sustainable manufacturing system design in which three facilities were considered, these are supplier $s$, factory $f$ and warehouse $w$ in order to option the optimal solution among conflicting objective including investment cost for establishing the manufacturing system, total energy consumption consumed by the manufacturing system and total $\mathrm{CO}_{2}$ emissions released from it.

3) The developed model can be used for designing the sustainable manufacturing system by taking into account the economic and ecological parameters towards a minimization of the total cost, the total energy consumption and $\mathrm{CO}_{2}$ emissions associated with relevant machines, air conditioning units and lighting bulbs involved in each manufacturing process and material flow.

4) The developed model was coded using LINGO $^{11}$ in which optimal solutions were obtained using two different solution approaches which are the $\varepsilon$-constraint approach and the LP-metrics approach, respectively. Subsequently, the performances of these approaches were compared in terms of both the solution quality and run time required. The best solution then was determined using the max-min approach. This helps in obtain the best sustainable manufacturing system design and it also reflects different prospects of decision makers or manufacturing system designers in different preferences.

5) Applicability of the developed model and proposed solution approaches was examined using collected data from a real case study.

6) The study concluded that the multi-objective mathematical model was useful as an aid for optimizing the manufacturing system design under the economic and ecological constraints. 


\begin{abstract}
A sustainable manufacturing system design can be defined as a process aimed at minimising the negative aspect of both economic and ecological costs. This may be partially achieved through the implementation of lean manufacturing methods in order to reduce production wastes, increase efficiency of manufacturing systems and minimise operational costs. Nevertheless, the concept of lean methods does not include environmental considerations in terms of such as energy consumption and $\mathrm{CO}_{2}$ (carbon dioxide) emissions, which are also important factors today for developing a sustainable manufacturing system. This paper addresses these issues involved in modelling a sustainable manufacturing system allowing an evaluation in energy consumption and $\mathrm{CO}_{2}$ emissions against the total cost using the multi-objective approach. In this work, a multi-objective mathematical model was developed based on a manufacturing system incorporating its economic and ecological parameters towards a minimization of the total cost, the total energy consumption and $\mathrm{CO}_{2}$ emissions associated with relevant machines, air conditioning units and lighting bulbs involved in each manufacturing process and material flow. The model was coded using LINGO $^{11}$ to help gain optimal solutions using the $\varepsilon$-constraint approach and the LP-metrics approach, respectively. The best solution among obtained optimal results was revealed using the max-min approach. Applicability of the proposed method was also examined using collected data from a real case study. The study concluded that the multi-objective mathematical model was useful as an aid for optimizing the manufacturing system design under the economic and ecological constraints.
\end{abstract}

Keywords: sustainable manufacturing systems, energy consumption, $\mathrm{CO}_{2}$, lean manufacturing, environmental constraints, multi-objectives.

\title{
1. Introduction
}

In the past decade, there has been an increasing awareness in development of sustainable manufacturing processes or systems as governments in many countries have been enforcing ever-stricter environmental policies and regulations in industry by promoting energy saving and low-emission manufacturing activities. Thus, system designers need not merely to apply traditional methods to improve system efficiency and productivity but also to examine the environmental impact on the developed system by incorporating economic and ecological constraints into their manufacturing systems design (Lind et al., 2008). In practice, a sustainable manufacturing system may be designed or implemented by addressing the environmental considerations as constraints or enforcing legislations that aim to mitigate environmental impacts by dealing with the environmental issues at an early stage. In this case, the environmental aspect is considered as a separate objective, together with other classical objectives such as system productivity, efficiency and costs to form a multi-objective optimization (MOO) problem (Taghdisian et al., 2015). Development of a sustainable manufacturing system design may also be achieved by applying lean methods to improve system efficiency and productivity without significantly additional investments. Lean manufacturing is a systematic approach to eliminate non-value added wastes in various forms and it enables continuous improvement. These wastes are identified as overproduction, waiting for parts to arrive, unnecessary movement of materials, overprocessing, unnecessary inventory, excess motion and rework (Wang et al., 2009). Nevertheless, the traditional lean manufacturing concept does not consider environmental wastes particularly in terms of energy consumption and $\mathrm{CO}_{2}$ emissions for such as manufacturing system design and evaluation; these wastes add no values on manufactured products and need also to be identified (Heilala et al., 2008; Nujoom et al., 2016a).

There are a few studies in considering environmental aspects relating to sustainable manufacturing systems design. The concept of manufacturing sustainability may be defined as the creation of manufactured products by minimizing the negative environmental impact on usage of energy or other natural resources (Nujoom et al., 2016a). Manufacturing companies ought to improve system efficiency and productivity without sacrificing the environment as return to achieve these goals (Pagell et al., 2004). Heilala et al., (2008) suggested that manufacturing system designers need to not merely rely on traditional methods in improvements of system efficiency and productivity but also incorporate environmental considerations into design and operation of manufacturing processes or systems. Rodger and George (2017) proposed a sustainable economic model under the triple bottom line (TBL) or the three pillars approach; which is the interdependencies between economic 
sectors, with national social and environmental concerns to construct a model in which financial aspects of performance can be expressed. The model preserves the positive dynamics of capitalism and accounting principles while improving collaboration between industry, landowners, and environmentalists to optimize return on profits for companies, it provide royalties to landowners, and satisfy the planet's environmental concerns. The study is very much in line with our model in term of economic and ecological considerations. The measures for economic performance are manufacturing cost, quality, responsiveness and flexibility. The environmental performance is all about how well an organization manages the environmental aspects of its activities, products, and services. The measures considered for environmental aspect of sustainability are material usage, energy usage, water usage, waste and emissions. Social performance assesses how well an organization has translated its social goals into practice. Social performance can be evaluated in terms of the impact of organization's decisions and activities on society that contribute towards sustainable development including health and welfare of society, stakeholder's expectations, compliance with applicable law and integration throughout the organization. The contrasting between their paper and our paper is a social performance outcomes, which is the third part of the TBL accounting. The present study focuses on two of the three pillars of sustainable development: economic and environmental considerations (the social pillar is not addressed in this paper) as two of the most important strategies to improve sustainability in manufacturing is to reduce the adverse environmental impacts of energy consumed and $\mathrm{CO}_{2}$ emissions during the manufacturing phase as energy consumption directly impacts economic progress (Jayal et al., 2010., Nishant et al., 2014., Pusavec et al., 2010 and Jawahir et al., 2011). Pishvaee and Razmi (2012) established a multi-objective fuzzy model for optimizing a green supply chain design in minimizing total costs as well as environmental impact. Gielen and Moriguchi (2002) developed a new linear programming model (namely the steel environmental strategy assessment program) to analyse and reduce the impact of $\mathrm{CO}_{2}$ emissions in the life cycle of iron and steel in Japan for the next three decades. Hidalgo et al., (2005) created a simulation model aimed to analyse the evolution of the world energy outlook for steel and iron industry from 1997 to 2030. Koc and Kaplan (2007) presented an investigation on energy consumption for a particular ring type yarn manufacturing system. Wang $e t$ al., (2008) proposed a process integration (PI) technique that was used for evaluating $\mathrm{CO}_{2}$ emissions for a steel industry. Li et al., (2009) used a multi-objective mixed integer non-linear mathematical model incorporating environmental considerations in terms of material flow and energy consumption into the chemical process synthesis at the initial design stage. Mohammed et al., (2016) applied a fuzzy tri-criterion programming model for minimization of the warehouse total cost, maximization of the warehouse capacity utilization, and minimization of the travel time of products from storage racks to collection points. Jamshidi et al., (2012) developed a multi-objective mathematical model considering the annual cost minimization and the effect of $\mathrm{NO}_{2}, \mathrm{CO}$ and volatile organic particles produced by facilities and transportation in the supply chain. AlçadaAlmeida et al. (2009) developed a multi-objective programming approach used for investigating the locations and capacities of hazardous material burning facilities under the social, economic, and environmental constraints. Wang et al., (2011) studied a multi-objective optimization model used for determining the trade-off decision between the total cost and the amount of $\mathrm{CO}_{2}$ emissions released from the supply chain facilities. Abdallah et al., (2010) applied a multi-objective optimization method for minimizing carbon emissions and investment cost of the supply chain network facilities. Shaw et al., (2012) selected the appropriate suppliers in the supply chain network using a fuzzy multi-objective linear programming approach that addresses the minimization of ordered quantity to the supplier and the total carbon emissions for sourcing of material. Zhou et al., (2009) selected suitable materials to develop sustainable products using a multi-objective approach with genetic algorithms. Hamdy et al., (2011) applied a multi-objective optimization method to minimize the $\mathrm{CO}_{2}$ emissions and the investment cost for a two-storey house and its Heating/cooling system. Pinto et al., (2011) developed a fuzzy linear programming and a mixed integer linear programming for designing supply chain structures for annual profit maximization, while considering environmental aspects. Fesanghary et al., (2012) developed a multi-objective programming approach to minimize the life cycle cost and $\mathrm{CO}_{2}$ emissions of the residential buildings. Sharafi and ELMekkawy (2014) proposed a novel approach for optimal design of hybrid renewable energy systems (HRES) including various generators and storage devices to minimize simultaneously the total cost of the system, unmet load, and fuel emissions. Sahar et al., (2014) proposed a multi-objective optimization model of a two-layer dairy supply chain aimed at minimizing $\mathrm{CO}_{2}$ emissions of transportation and the total cost for product distribution. Bortolini et al., (2016) proposed a three-objective distribution planner to 
tackle the tactical optimization issue of a fresh food distribution network. The optimization objectives were to minimize operating cost, carbon footprint and delivery time; the work, however, did not consider other costs and the effect of uncertainty that may occur. Paksoy et al., (2012) provided a fuzzy multi-objective model for designing a green closed-loop supply chain network aimed at minimizing all the transportation costs for the supply chain's forward and reverse logistics and total $\mathrm{CO}_{2}$ emissions. Harris et al., (2014) proposed a multiobjective optimization approach for solving a facility location-allocation problem for a supply chain network where financial costs and $\mathrm{CO}_{2}$ emissions are considered as objectives.

This paper presents an investigation into a sustainable manufacturing system design through the development of a multi-objective optimization model seeking a compromised solution based on a number of conflicting objectives. These objectives are aimed at minimizing the total investment cost, the amount of energy consumption and $\mathrm{CO}_{2}$ emissions. The developed model was coded using LINGO ${ }^{11}$ in which optimal solutions were obtained using the $\varepsilon$-constraint approach and the LP-metrics approach, respectively. The best solution was determined using the max-min approach. Applicability of the proposed method was also examined through a real case study.

\section{Problem statement and model formulation}

Energy and $\mathrm{CO}_{2}$ emissions are generated often by using combusting fossil fuels or renewable resources that produce such as thermal heat or electricity used by facilities in a manufacturing system. Figure 1 illustrates the sustainable manufacturing system design in which three facilities were considered, these are supplier $s$, factory $f$ and warehouse $w$. The facility may consist of operation machines, air conditioning units, lighting bulbs and other supportive equipment such as compressors that supply compressed air to some operation machines. Between facilities, there are transportation vehicles to be used. In order to quantify energy consumption and $\mathrm{CO}_{2}$ emissions of facilities in a manufacturing system, a multi-objective optimization model was formulated based on the proposed sustainable manufacturing system design. The model was used for obtaining a trade-off decision towards the minimization of the total investment cost for establishing the manufacturing system, the total energy consumption by the manufacturing system, and the total amount of $\mathrm{CO}_{2}$ emissions. These objectives are in conjunction with (i) numbers of operation machines, air conditioning units and lighting bulbs and (ii) quantity of materials flows in the manufacturing system.

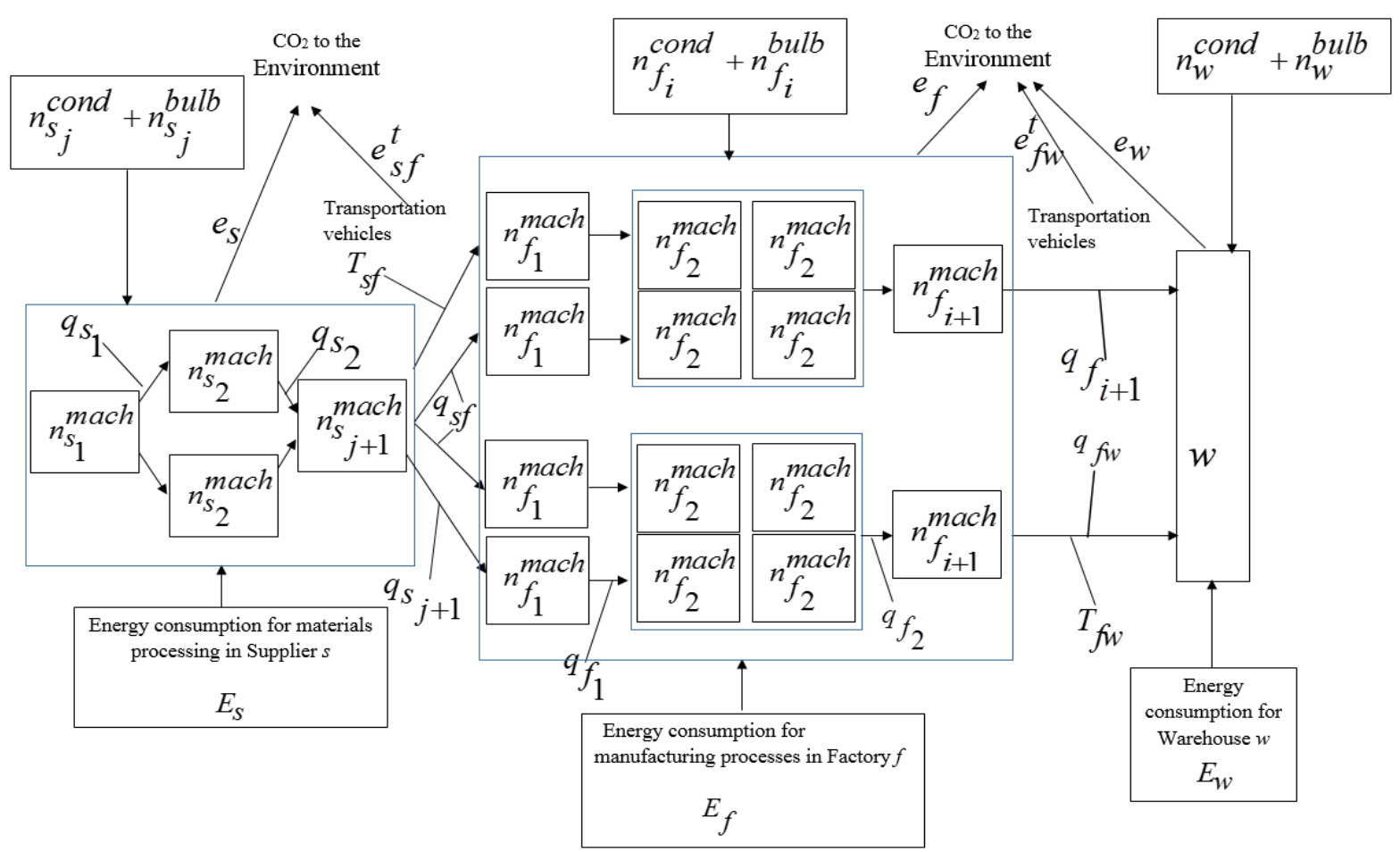


Figure 1. A sustainable manufacturing system design

The model was formulated based on the following assumptions:

- Supplier $s$ must satisfy all demands of a factory $f$ and a warehouse $w$ at any time.

- The potential locations of a supplier or a factory are known.

- Supplier and factory have a certain capacity.

- Breakdown is not considered for all facilities used in this case study

- Compressor system, air conditioning units and illumination bulbs are powered by electricity

\subsection{Notations}

Sets, parameters and decision variables are used as follows:

Sets

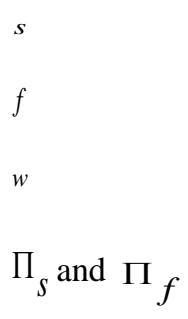

Parameters

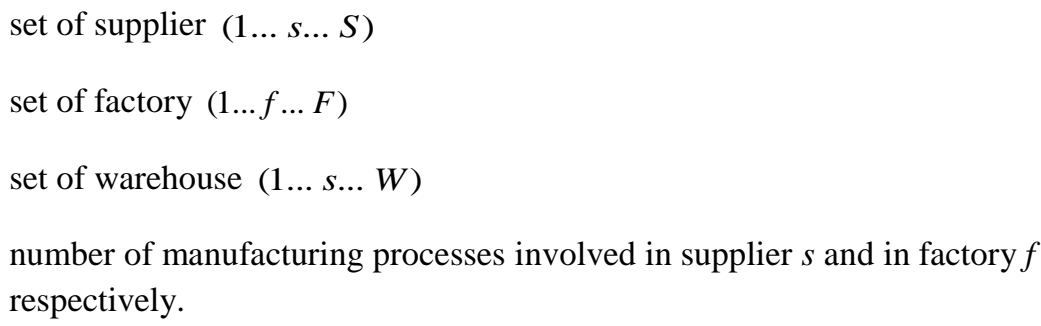

cost required (GBP) for establishing facility $l$, where $l \in\{s, f, w\}$

cost of machines (GBP) involved in process $j$ in facility $s$ and involved in process $i$ in facility $f$ respectively, where, $j \in\left\{1,2, \ldots ., \Pi_{s}\right\}$ and $i \in\left\{1,2, \ldots, \Pi_{f}\right\}$

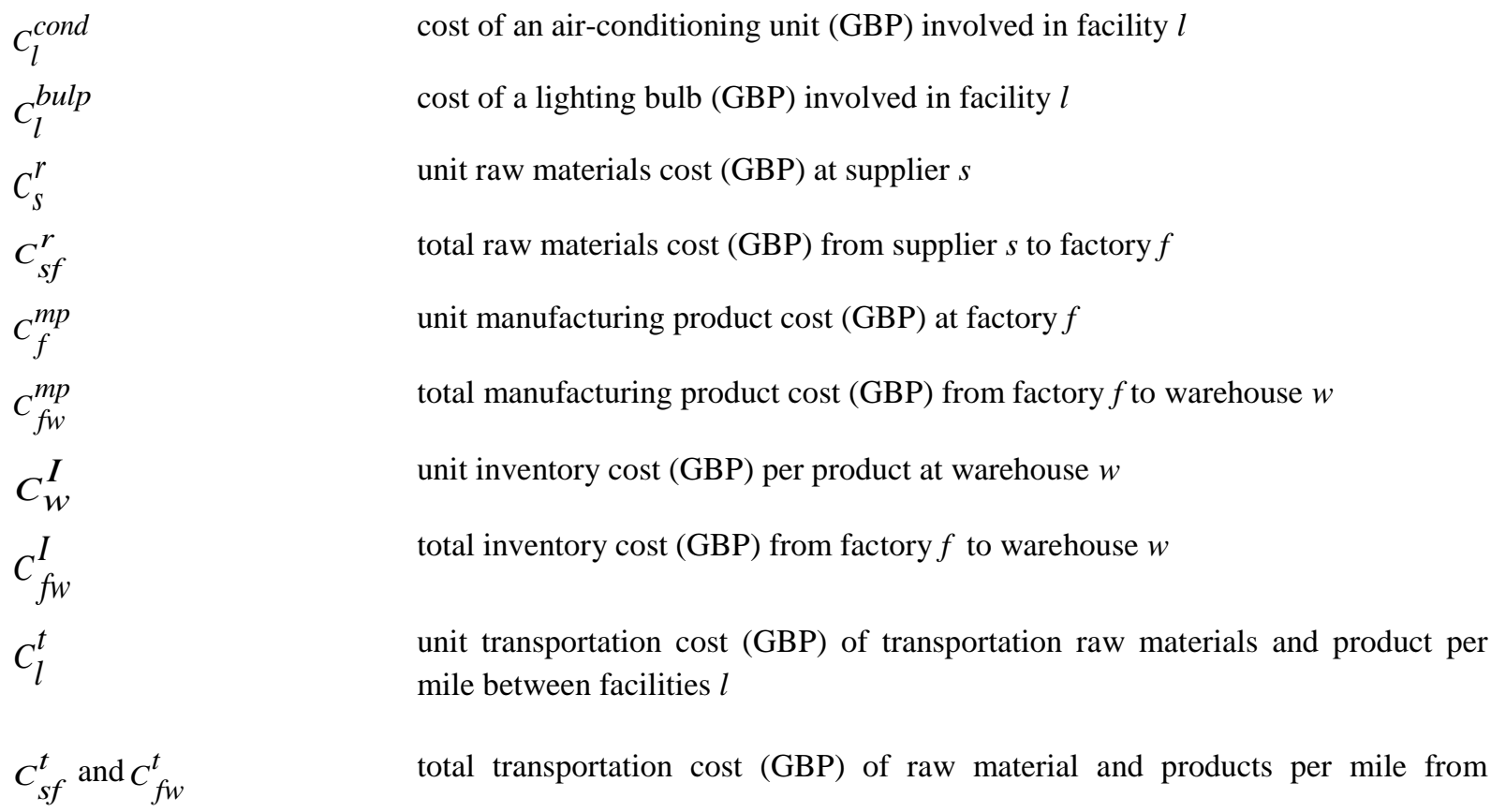
mile between facilities $l$

total transportation cost (GBP) of raw material and products per mile from 
supplier $s$ to factory $f$ and from factory $f$ to warehouse $w$ respectively

$C_{l}^{t}$

$T_{s f}$ and $T_{f w}$

$\mathrm{Ca}$

$D_{f}$ and $D_{w}$

$E_{s}, E_{f}$ and $E_{w}$

$E_{s_{j}}^{\text {mach }}$ and $E_{f_{i}}^{m a c h}$

$E_{s_{j}}^{c o n d}$ and $E_{f_{i}}^{c o n d}$

$E_{s_{j}}^{b u l b}$ and $E_{f_{i}}^{b u l b}$

$E_{s_{j}}^{c o m p}$ and $E_{f_{i}}^{c o m p}$

$E_{w}^{c o n d}$ and $E_{w}^{b u l b}$

$N_{s_{j}}^{\text {mach }}$ and $N_{f_{i}}^{\text {mach }}$

$\mathfrak{R}_{s_{j}}$ and $\mathfrak{R} f_{i}$

$\tau_{s_{j}}$ and $\tau_{f_{i}}$

$\mu_{s_{j} \text { and }} \mu_{f_{i}}$

$N_{s_{j}}^{\text {cond } \text { and }} N_{f_{i}}^{\text {cond }}$

$N_{s_{j}}^{b u l b}$ and $N_{f_{i}}^{b u l b}$

$N_{s_{j}}^{\text {comp and }} N_{f_{i}}^{\text {comp }}$

$\wp_{s}, \wp_{f}$ and $\wp_{w}$ the total cost of transportation of raw materials and manufacturing products per mile between facilities $l$, where $l \in\{s, f, w\}$

distance (miles) from supplier $s$ to factory $f$ and from factory $f$ to warehouse $w$

maximum operations capacity $(\mathrm{kg})$ of facility $l$

minimum demand $(\mathrm{kg})$ of factory $f$ and warehouse $w$

total energy consumption ( $\mathrm{kWh}$ ) for supplier $s$, for factory $f$ and for warehouse $w$ respectively

energy consumption (kWh) for a machine involved in process $j$ at supplier $s$ and in process $i$ at factory $f$ respectively,

where $j \in\left\{1,2, \ldots ., \Pi_{s}\right\}$ and $i \in\left\{1,2, \ldots ., \Pi_{f}\right\}$

energy consumption $(\mathrm{kWh})$ for the air-conditioning units involved in process $j$ at supplier $s$ and in process $i$ at factory $f$ respectively

energy consumption $(\mathrm{kWh})$ for the lighting bulbs involved in process $j$ at supplier $s$ and in process $i$ at factory $f$ respectively

energy consumption ( $\mathrm{kWh}$ ) of compressed air needed for a machine involved in process $j$ at supplier $s$ and in process $i$ at factory $f$ respectively

energy consumption (kWh) for the air-conditioning units and lighting bulbs at warehouse $w$ respectively

installed power $(\mathrm{kw})$ for a machine involved in process $j$ at supplier $s$ and in process $i$ at factory $f$ respectively

manufacturing rate $(\mathrm{kg} / \mathrm{h})$ for a machine involved in process $j$ at supplier $s$ and in process $i$ at factory $f$ respectively

operating time (hr) for a machine involved in process $j$ at supplier $s$ and in process $i$ at factory $f$ respectively

efficiency (\%) for a machine involved in process $j$ at supplier $s$ and in process $i$ at factory $f$ respectively

installed power (kw) for an air-conditioning unit involved in process $j$ at supplier $s$ and in process $i$ at factory $f$ respectively

installed power ( $\mathrm{kW}$ ) for a lighting bulb involved in process $j$ at supplier $s$ and in process $i$ at factory $f$ respectively

installed power $(\mathrm{kw})$ for a compressor at supplier $s$ and at factory $f$ respectively

mass production $(\mathrm{kg} / \mathrm{month})$ from supplier $s$, from factory $f$ and stored at 
warehouse $w$ respectively

$$
\begin{aligned}
& \Psi_{s_{j}} \text { and } \Psi_{f_{i}} \\
& v_{s_{j}}^{c o m p} \text { and } v_{f_{i}}^{c o m p} \\
& \rho_{S}^{\text {comp }} \text { and } \rho_{f}^{\text {comp }} \\
& \Phi_{s_{j}}^{\text {cond }} \text { and } \Phi_{f_{i}}^{\text {cond }} \\
& \varphi_{s_{j}}^{b u l b} \text { and } \varphi_{f_{i}}^{b u l b} \\
& \Gamma_{w}^{c o n d} \\
& \lambda_{w}^{b u l b} \\
& e_{s_{j}}^{m a c h} \text { and } e_{f_{i}}^{\text {mach }} \\
& e_{s_{j}}^{\text {cond }} \text { and } e_{f_{i}}^{\text {cond }} \\
& e_{s_{j}}^{b u l b} \text { and } e_{f_{i}}^{b u l b} \\
& e_{s_{j}}^{c o m p} \text { and } e_{f_{i}}^{c o m p} \\
& e_{w}^{c o n d} \text { and } e_{w}^{b u l b} \\
& e_{s f}^{t} \text { and } e_{f w}^{t} \\
& e_{s} \\
& e^{t}
\end{aligned}
$$$$
e_{f}
$$$$
e_{w}
$$$$
V
$$$$
\omega_{s_{j}}, \omega_{f_{i}} \text { and } \omega_{w}
$$

total waste ratio $(\%)$ for a machine involved in process $j$ at supplier $s$ and in process $i$ at factory $f$ respectively

compressed air $\left(\mathrm{m}^{3} / \mathrm{h}\right)$ used for a machine involved in process $j$ at supplier $s$ and in process $i$ at factory $f$ respectively

the capacity of a compressor $\left(\mathrm{m}^{3} / \mathrm{h}\right)$ at supplier $s$ and at factory $f$ respectively

covering rate per air-conditioning unit (unit) that serves machines involved in process $j$ at supplier $s$ and in process $i$ at factory $f$ respectively

covering rate of lighting bulbs (unit) per one machine involved process $j$ at supplier $s$ and in process $i$ at factory $f$ respectively

covering rate per air-conditioning unit $(\mathrm{kg})$ that services quantity of products in warehouse $w$

covering rate per lighting bulb $(\mathrm{kg})$ that services quantity of products in warehouse $w$

amount of $\mathrm{CO}_{2}$ emissions $(\mathrm{kg})$ released from the machines involved in process $j$ of supplier $s$ and in process $i$ of factory $f$ respectively

amount of $\mathrm{CO}_{2}$ emissions $(\mathrm{kg})$ released from the air-conditioning units involved in process $j$ of supplier $s$ and in process $i$ of factory $f$ respectively

amount of $\mathrm{CO}_{2}$ emissions $(\mathrm{kg})$ released from the lighting bulbs involved in process $j$ of supplier $s$ and in process $i$ of factory $f$ respectively

amount of $\mathrm{CO}_{2}$ emissions $(\mathrm{kg})$ released from a compressor system involved in process $j$ of supplier $s$ and in process $i$ of factory $f$ respectively

amount of $\mathrm{CO}_{2}$ emissions $(\mathrm{kg})$ released from air-conditioning units and the lighting bulbs involved in warehouse $w$

amount of $\mathrm{CO}_{2}$ emissions $(\mathrm{kg})$ released for transportation from supplier $s$ to factory $f$ and from factory $f$ to warehouse $w$ respectively

the total amount of $\mathrm{CO}_{2}$ emissions $(\mathrm{kg})$ released from supplier $s$

the total amount of $\mathrm{CO}_{2}$ emissions $(\mathrm{kg})$ released from transportation vehicles duo to transferring materials from supplier $s$ to factory $f$ and shipped the products from factory $f$ to warehouse $w$

the total amount of $\mathrm{CO}_{2}$ emissions $(\mathrm{kg})$ released from factory $f$

the total amount of $\mathrm{CO}_{2}$ emissions $(\mathrm{kg})$ released from warehouse $w$

capacity (units) per vehicle

$\mathrm{CO}_{2}$ emission factor $(\mathrm{kg} / \mathrm{kWh})$ at supplier $s$, at factory $f$ and warehouse $w$ respectively 


$$
\omega_{s f}^{t} \text { and } \omega_{f w}^{t}
$$

Decision variables

$$
\begin{aligned}
& q_{s_{j}}^{r} \text { and } q_{f_{i}}^{r} \\
& q_{s_{(j+1)}}^{r} \text { and } q_{f_{(i+1)}}^{r} \\
& q_{s f}^{r} \text { and } q_{f w}^{m p} \\
& n_{s_{j}}^{m a c h} \text { and } n_{f_{i}}^{m a c h} \\
& n_{s_{j}}^{c o n d}, n_{f_{i}}^{\text {cond } \text { and } n_{w}^{\text {cond }}} \\
& n_{s_{j}}^{b u l b}, n_{f_{i}}^{b u l b} \text { and } n_{w}^{b u l b}
\end{aligned}
$$

factory $f$ and from factory $f$ to warehouse $w$ respectively

mass of material $(\mathrm{kg})$ involved in process $j$ in supplier $s$ and in process $i$ in factory $f$ respectively where, $j \in\left\{1,2, \ldots ., \Pi_{s}\right\}$ and $i \in\left\{1,2, \ldots ., \Pi_{f}\right\}$ mass of material $(\mathrm{kg})$ transferred from the machines involved in process $j$ in supplier $s$ and in process $i$ in factory $f$ respectively

mass of material $(\mathrm{kg})$ transported from supplier $s$ to factory $f$ and products transported

from factory $f$ to warehouse $\mathrm{w}$

number of machines (unit) involved in process $j$ in supplier $s$ and in process $i$ in factory $f$ respectively.

number of air-conditioning units (unit) involved in process $j$ in supplier $s$, in process $i$ in factory $f$ and in warehouse $w$ respectively

number of lighting bulbs (unit) involved in process $j$ in supplier $s$, in process $i$ in factory $f$ and in warehouse $w$ respectively

Thus, the multi-objective mathematical model is formulated as follows:

\section{Objective function 1: Minimization of total investment cost $\Lambda_{1}$}

In the proposed sustainable manufacturing system design, the total investment cost is a combination of fixed cost (costs of the land, buildings, equipment, services and salaries), costs of raw materials and transportation of raw materials, and costs of manufacturing and inventory and so on. Thus, the total investment cost $\Lambda_{1}$ can be minimised as follows:

$$
\begin{aligned}
& \text { Min } \Lambda_{1}=C_{l}^{e s}+C_{s}^{\text {mach }}+C_{f}^{\text {mach }}+C_{s}^{\text {cond }}+C_{f}^{\text {cond }}+C_{w}^{\text {cond }} \\
& +C_{s}^{b u l p}+C_{f}^{\text {bulp }}+C_{w}^{b u l p}+C_{s f}^{r}+C_{f w}^{m p}+C_{l}^{t}+C_{f w}^{I}
\end{aligned}
$$

Where, the total cost required for establishing facility $l C_{l}^{e s}$, where $l \in\{s, f, w\}$ is given as bellow:

$$
C_{l}^{e s}=C_{s}^{e s}+C_{f}^{e s}+C_{w}^{e s}
$$

Cost required for establishing supplier $s$, factory $f$ and warehouse $w\left(C_{s}^{e s}, C_{f}^{e s}\right.$ and $\left.C_{w}^{e s}\right)$ is given respectively as follows:

$$
\begin{aligned}
& C_{S}^{e s}=C_{S}^{\text {land }}+C_{S}^{\text {building }} \\
& +C_{S}^{\text {equipment }}+C_{S}^{\text {services }}+C_{S}^{\text {saleries }}
\end{aligned}
$$


$C_{f}^{e s}=C_{f}^{\text {land }}+C_{f}^{\text {building }}$

$+C_{f}^{\text {equipment }}+C_{f}^{\text {services }}+C_{f}^{\text {saleries }}$

$C_{w}^{e s}=C_{w}^{l a n d}+C_{w}^{\text {building }}$

$+C_{w}^{\text {equipment }}+C_{w}^{\text {services }}+C_{w}^{\text {saleries }}$

Cost of the machines $C_{s}^{\text {mach }}$ and $C_{f}^{\text {mach }}$ involved in process $j$ at supplier $s$ and in process $i$ at factory $f$ is given respectively as follows:

$$
\begin{aligned}
C_{s}^{\text {mach }} & =\sum_{j=1}^{\Pi_{s}}\left(C_{s_{j}}^{\text {mach }} n_{s_{j}}^{\text {machin }}\right) \\
C_{f}^{\text {mach }} & =\sum_{i=1}^{\prod_{f}}\left(C_{f_{i}}^{\text {mach }} n_{f_{i}}^{\text {machin }}\right)
\end{aligned}
$$

Cost of an air-conditioning unit $C_{S}^{c o n d}, C_{f}^{c o n d}$ and $C_{w}^{c o n d}$ involved in process $j$ at supplier $s$, involved in process $i$ at factory $f$ and involved in warehouse $w$ is given respectively by the following equations:

$$
\begin{aligned}
& C_{s}^{\text {cond }}=\sum_{j=1}^{\prod_{S}}\left(C_{s_{j}}^{\text {cond }} n_{s_{j}}^{\text {cond }}\right) \\
& C_{f}^{\text {cond }}=\sum_{j=1}^{\prod_{f}}\left(C_{f_{i}}^{\text {cond }} n_{f_{i}}^{\text {cond }}\right) \\
& C_{w}^{\text {cond }}=\sum_{w \in W}\left(C_{w}^{\text {cond }} n_{w}^{\text {cond }}\right)
\end{aligned}
$$

Cost of a lighting bulb $C_{s}^{b u l p}, C_{f}^{b u l p}$ and $C_{w}^{b u l p}$ involved in process $j$ at supplier $s$, involved in process $i$ at factory $f$ and involved in warehouse $w$ is given respectively by the following equations:

$$
\begin{aligned}
& C_{s}^{\text {bulp }}=\sum_{j=1}^{\prod_{S}}\left(C_{s_{j}}^{\text {bulp }} n_{s_{j}}^{\text {bulb }}\right) \\
& C_{f}^{\text {bulp }}=\sum_{i=1}^{\prod_{f}}\left(C_{f_{i}}^{\text {bulp }} n_{f_{i}}^{\text {bulb }}\right) \\
& C_{w}^{\text {bulb }}=\sum_{w \in W}\left(C_{w}^{\text {bulb }} n_{w}^{\text {bulb }}\right)
\end{aligned}
$$

The total cost of raw materials at supplier $s C_{s f}^{r}$ is calculated as bellow:

$$
C_{s f}^{r}=\sum_{s=1}^{S} \sum_{f=1}^{F} C_{S}^{r} q_{s f}^{r}
$$


The total cost of manufacturing products at factory $f C_{f w}^{m p}$ is given by the following equation:

$$
C_{f w}^{m p}=\sum_{f=1}^{F} \sum_{w=1}^{W} C_{f}^{m p} q_{f w}^{m p}
$$

The total cost of transportation of raw materials per mile between $s$ and $f C_{s f}^{t}$ is given as follows:

$$
C_{s f}^{t}=\sum_{s=1}^{S} \sum_{f=1}^{F} C_{s f}^{t} \frac{q_{s f}^{r}}{V} T_{s f}
$$

The total cost of transportation of products per mile between $f$ and $w C_{f w}^{t}$ is given as follows:

$$
C_{s f}^{t}=\sum_{s=1}^{S} \sum_{f=1}^{F} C_{s f}^{t} \frac{q_{s f}^{r}}{V} T_{s f}
$$

Total cost of inventory $C_{f w}^{I}$ at warehouse $w$ is determined as below:

$$
C_{f w}^{I}=\sum_{f=1}^{F} \sum_{w=1}^{W} C_{w}^{I} q_{f w}^{m p}
$$

Hence, equation (1) can be expressed as follows:

Min $\mathrm{Z}_{1}=C_{S}^{\text {land }}+C_{S}^{\text {building }}+C_{S}^{\text {equipment }}+C_{S}^{\text {services }}+C_{S}^{\text {saleries }}$

$+C_{f}^{\text {land }}+C_{f}^{\text {building }}+C_{f}^{\text {equipment }}+C_{f}^{\text {services }}+C_{f}^{\text {saleries }}+C_{w}^{\text {land }}$

$+C_{w}^{\text {building }}+C_{w}^{\text {equipment }}+C_{w}^{\text {services }}+C_{w}^{\text {saleries }}+\sum_{j=1}^{\prod_{s}}\left(C_{s_{j}}^{\text {mach }} n_{s_{j}}^{\text {mach }}\right)$

$+\sum_{i=1}^{\Pi_{f}}\left(C_{f_{i}}^{\text {mach }} n_{f_{i}}^{\text {mach }}\right)+\sum_{j=1}^{\Pi_{s}}\left(C_{s_{j}}^{\text {cond }} n_{s_{j}}^{\text {cond }}\right)+\sum_{j=1}^{\Pi_{f}}\left(C_{f_{i}}^{\text {cond }} n_{f_{i}}^{\text {cond }}\right)$

$+\sum_{w=1}^{W}\left(C_{w}^{\text {cond }} n_{w}^{\text {cond }}\right)+\sum_{j=1}^{\Pi_{S}}\left(C_{s_{j}}^{\text {bulp }} n_{s_{j}}^{\text {bulb }}\right)+\sum_{i=1}^{\Pi_{f}}\left(C_{f_{i}}^{\text {bulp }} n_{f_{i}}^{\text {bulb }}\right)$

$+\sum_{w=1}^{W}\left(C_{w}^{b u l p} n_{w}^{b u l b}\right)+\sum_{s=1}^{S} \sum_{f=1}^{F} C_{S}^{r} q_{s f}^{r}+\sum_{f=1}^{F} \sum_{w=1}^{W} C_{f}^{m p} q_{f w}^{m p}$

$+\sum_{s=1}^{S} \sum_{f=1}^{F} C_{s f}^{t} \frac{q_{s f}^{r}}{V} T_{s f}+\sum_{f=1}^{F} \sum_{w=1}^{W} C_{f w}^{t} \frac{q_{f w}^{m p}}{V} T_{f w}+\sum_{f=1}^{F} \sum_{w=1}^{W} C_{w}^{I} q_{f w}^{m p}$ 


\section{Objective function 2: Minimization of total energy consumption $\Lambda_{2}$}

The total energy consumption can be minimized as follows:

$\operatorname{Min} \Lambda_{2}=E_{s}+E_{f}+E_{w}$

Where, total energy consumption $E_{S}$ for supplier $s$ is given by:

$E_{S}=\sum_{j=1}^{\Pi_{S}}\left[E_{s_{j}}^{\text {mach }}+E_{s_{j}}^{\text {cond }}+E_{s_{j}}^{\text {bulb }}+E_{s_{j}}^{c o m p}\right]$, where $j \in\left\{1,2, \ldots ., \Pi_{s}\right\}$

Energy consumption $E_{s_{j}}^{\text {mach }}, E_{s_{j}}^{c o n d}$ and $E_{s_{j}}^{b u l b}$ for machines, air-conditioning units and lighting bulbs involved in process $j$ at supplier $s$ are given respectively by:

$$
\begin{aligned}
& E_{s_{j}}^{\text {mach }}=\sum_{j=1}^{\prod_{S}}\left(\frac{q_{s_{j}}^{r}}{\Re_{s_{j}} \mu_{s_{j}}} N_{s_{j}}^{\text {mach } n_{s_{j}}^{\text {mach }}}\right) \\
& E_{s_{j}}^{\text {cond }}=\sum_{j=1}^{\Pi_{S}}\left(N_{s_{j}}^{\text {cond }} n_{s_{j}}^{\text {cond }} \frac{q_{s_{(j+1)}}^{r}}{\wp_{s}}\right) \\
& E_{s_{j}}^{\text {bulb }}=\sum_{j=1}^{\prod_{S}}\left(N_{s_{j}}^{\text {bulb } n_{s_{j}}^{\text {bulb }} \frac{q_{s_{(j+1)}}^{r}}{\wp_{s}}}\right)
\end{aligned}
$$

Energy consumption of compressed air $E_{s_{j}}^{\text {comp }}$ which is needed for machines involved in process $j$ at supplier $s$, is calculated by:

$$
E_{s_{j}}^{c o m p}=\sum_{j=1}^{\Pi_{s}}\left(\frac{q_{s_{j}}^{r}}{\mathfrak{R}_{s_{j}} \mu_{s_{j}}} \frac{N_{\rho_{j}}^{c o m p}}{\rho_{s_{j}}^{c o m p}} v_{s_{j}}^{\text {comp }} n_{s_{j}}^{\text {mach }}\right)
$$

Total energy consumption $E_{f}$ for factory $f$ is given by:

$E_{f}=\sum_{i=1}^{\Pi}\left[E_{f_{i}}^{\text {mach }}+E_{f i}^{\text {cond }}+E_{f_{i}}^{\text {bulb }}+E_{f_{i}}^{c o m p}\right]$, where, $i \in\left\{1,2, \ldots ., \Pi_{f}\right\}$

Energy consumption $E_{f_{i}}^{\text {mach }}, E_{f_{i}}^{\text {cond }}$ and $E_{f_{i}}^{b u l b}$ for machines, air-conditioning units and lighting bulbs involved in process $i$ at factory $f$ is given respectively by: 


$$
\begin{aligned}
& E_{f_{i}}^{\text {mach }}=\sum_{i=1}^{\Pi_{f}}\left(N_{f_{i}}^{\text {mach }} n_{f i}^{\text {mach }} \frac{q_{f_{i}}^{r}}{\Re_{f_{i}} \mu_{f_{i}}}\right) \\
& E_{f_{i}^{\text {cond }}}^{\prod_{f}}=\sum_{i=1}^{\Pi_{f}}\left(N_{f_{i}}^{\text {cond }} n_{f_{i}}^{\text {cond }} \frac{q_{f_{(i+1)}^{r}}^{r}}{\wp f}\right) \\
& E_{f_{i}^{b u l b}}^{\text {but }}=\sum_{i=1}^{\prod_{f}}\left(N_{f_{i}}^{\text {bulb }} n_{f_{i}}^{\text {bulb }} \frac{q_{f_{(i+1)}}^{r}}{\wp f}\right)
\end{aligned}
$$

Energy consumption of compressed air $E_{f_{i}}^{c o m p}$ needed for machines involved in process $i$ at factory $f$ is calculated by:

$$
E_{f_{i}}^{\text {comp }}=\sum_{i=1}^{\Pi_{f}}\left(\frac{q_{f_{i}}^{r}}{\Re_{f_{i} \mu_{f i}}} \frac{N_{f_{i}}^{\text {comp }}}{\rho_{f_{i}}^{\text {comp }}} v_{f_{i}}^{\text {comp }} n_{f_{i}}^{\text {mach }}\right)
$$

Total energy consumption $E_{w}$ for warehouse $w$ is given by:

$$
E_{w}=\sum_{w=1}^{W}\left(E_{W}^{c o n d}+E_{W}^{b u l b}\right)
$$

Energy consumption $E_{w}^{c o n d}$ and $E_{w}^{b u l b}$ for air-conditioning units and lighting bulbs at warehouse $w$, are given by:

$$
\begin{aligned}
& E_{w}^{\text {cond }}=\sum_{w=1}^{W}\left(N_{w}^{c o n d} n_{w}^{c o n d} \frac{q_{f w}^{m p}}{\wp_{w}}\right) \\
& E_{w}^{b u l b}=\sum_{w=1}^{W}\left(N_{w}^{b u l b} n_{w}^{b u l b} \frac{q_{f w}^{m p}}{\wp_{w}}\right)
\end{aligned}
$$


Hence, equation (19) is given as follows:

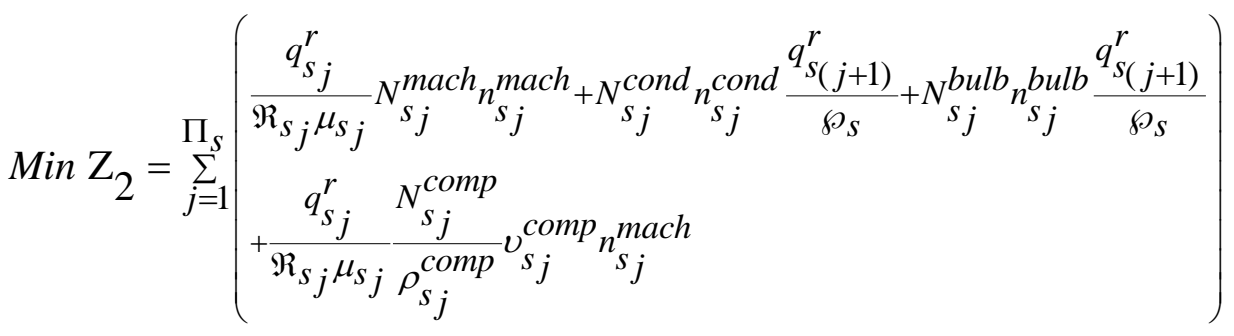

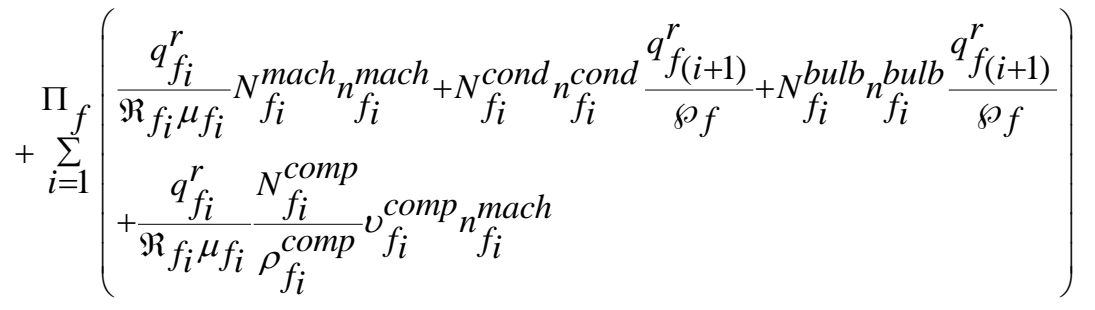

$$
\begin{aligned}
& +\sum_{w=1}^{W}\left(N_{w}^{c o n d} n_{w}^{c o n d} \frac{q_{w}^{m p}}{\wp_{w}}+N_{w}^{b u l b} n_{w}^{b u l b} \frac{q_{f w}^{m p}}{\wp_{w}}\right)
\end{aligned}
$$

\section{Objective function 3: Minimization of total $\mathrm{CO}_{2}$ emissions $\Lambda_{3}$}

The total amount of $\mathrm{CO}_{2}$ emissions can be minimized below:

$\operatorname{Min} \Lambda_{3}=e_{s}+e^{t}+e_{f}+e_{w}$

Where, the total amount of $\mathrm{CO}_{2}$ emissions $e_{S}$ released from supplier $s$ is calculated as follows:

$$
e_{S}=\sum_{j=1}^{\prod_{S}}\left[e_{s_{j}}^{\text {mach }}+e_{s_{j}}^{\text {cond }}+e_{s_{j}}^{\text {bulb }}+e_{s_{j}}^{\text {comp }}\right]
$$

Amount of $\mathrm{CO}_{2}$ emissions $e_{s_{j}}^{\text {mach }}, e_{s_{j}}^{\text {cond }}$ and $e_{s_{j}}^{b u l b}$ released from the machines, air-conditioning units and lighting bulbs involved in process $j$ at supplier $s$, is respectively given by:

$$
\begin{gathered}
e_{s_{j}}^{\text {mach }}=\sum_{j=1}^{\prod_{S}}\left(\omega_{s_{j}} E_{s_{j}}^{\text {mach }} q_{s_{j}}^{r}\right) \\
e_{s_{j}}^{\text {cond }}=\sum_{j=1}^{\Pi_{S}}\left(0.689 E_{s_{j}}^{\text {cond }}\right) \\
e_{s_{j}}^{\text {bulb }}=\sum_{j=1}^{\prod_{S}}\left(0.689 E_{s_{j}}^{\text {bulb }}\right)
\end{gathered}
$$


Amount of $\mathrm{CO}_{2}$ emissions $e_{s}^{c o m p}$ released from a compressor system involved in process $j$ of supplier $s$ as below:

$e_{s_{j}}^{c o m p}=\sum_{j=1}^{\Pi_{S}}\left(0.689 E_{s_{j}}^{\text {comp }}\right)$, where 0.689 is the emission factor for the electricity

The total amount of $\mathrm{CO}_{2}$ emissions $e^{t}$ which are released for transportation from supplier $s$ to factory $f$ and from factory $f$ to warehouse $w$, is given below:

$e^{t}=e_{s f}^{t}+e_{f w}^{t}$

Where, amount of $\mathrm{CO}_{2}$ emissions $e_{s f}^{t}$ and $e_{f w}^{t}$ which are released for transporting raw material from supplier $s$ to factory $f$ and products from factory $f$ to warehouse $w$ respectively is given below:

$$
\begin{aligned}
& e_{s f}^{t}=\sum_{s=1}^{S} \sum_{f=1}^{F}\left(\omega_{s f}^{t} \frac{q_{s f}^{r}}{V} T_{s f}\right) \\
& e_{f w}^{t}=\sum_{f=1}^{F} \sum_{w=1}^{W}\left(\omega_{f w}^{t} \frac{q_{f w}^{m p}}{V} T_{f w}\right)
\end{aligned}
$$

The total amount of $\mathrm{CO}_{2}$ emissions $e_{f}$ released from factory $f$ is calculated as below:

$e_{f}=\sum_{i=1}^{\Pi} f\left[e_{f_{i}}^{\text {mach }}+e_{f_{i}}^{\text {cond }}+e_{f_{i}}^{\text {bulb }}+e_{f_{i}}^{\text {comp }}\right]$

Amount of $\mathrm{CO}_{2}$ emissions $e_{f_{i}}^{\text {mach }}, e_{f_{i}}^{\text {cond }}$ and $e_{f_{i}}^{b u l b}$ released from the machines, air-conditioning units and lighting bulbs involved in process $i$ at factory $f$ is given respectively by:

$$
\begin{aligned}
& e_{f_{i}}^{\text {mach }}=\sum_{i=1}^{\Pi_{f}}\left(\omega_{f_{i}} \frac{q_{f_{i}}^{r}}{\mathfrak{R}_{f_{i}} \mu_{f_{i}}} N_{f_{i}}^{\text {mach }} n_{f i}^{\text {mach }}\right) \\
& e_{f_{i}}^{\text {cond }}=\sum_{i=1}^{\Pi_{f}}\left(0.689 N_{f_{i}}^{\text {cond }} n_{f_{i}}^{\text {cond }} \frac{q_{f_{(i+1)}}^{r}}{\wp f}\right) \\
& e_{f_{i}}^{b u l b}=\sum_{i=1}^{\prod_{f}}\left(0.689 N_{f_{i}}^{b u l b} n_{f_{i}}^{b u l b} \frac{q_{f_{(i+1)}}^{r}}{\wp f}\right)
\end{aligned}
$$

Amount of $\mathrm{CO}_{2}$ emissions $e_{f_{i}}^{c o m p}$ released from a compressor system involved in process $i$ at factory $f$ as below: 
$e_{f_{i}}^{\text {comp }}=\sum_{i=1}^{\Pi_{f}}\left(0.689 \frac{q_{f_{i}}^{r}}{\mathfrak{R}_{f i} \mu_{f i}} \frac{N_{f_{i}}^{\text {comp }}}{\rho_{f_{i}}^{\text {comp }}} v_{f_{i}}^{\text {comp }} n_{f_{i}}^{\text {mach }}\right)$

Where 0.689 is the emission factor for the electricity

Amount of $\mathrm{CO}_{2}$ emissions $e_{w}$ released from warehouse $w$ is calculated as below:

$e_{w}=0.989 \sum_{w=1}^{W}\left(N_{w}^{c o n d} n_{w}^{c o n d} \frac{q_{f w}^{m p}}{\wp_{w}}+N_{w}^{b u l b} n_{w}^{b u l b} \frac{q_{f w}^{m p}}{\wp_{w}}\right)$

Thus, equation (32) is given as follows:

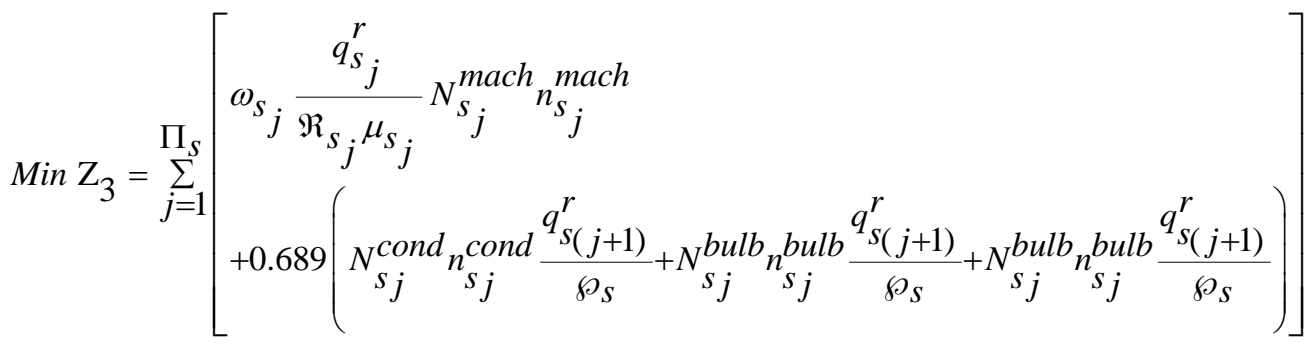

$$
\begin{aligned}
& +\sum_{s=1}^{S} \sum_{f=1}^{F}\left(\omega_{s f}^{t} \frac{q_{s f}^{r}}{V} T_{s f}\right)+\sum_{f=1}^{F} \sum_{w=1}^{W}\left(\omega_{f w}^{t} \frac{q_{f w}^{m p}}{V} T_{f w}\right)
\end{aligned}
$$

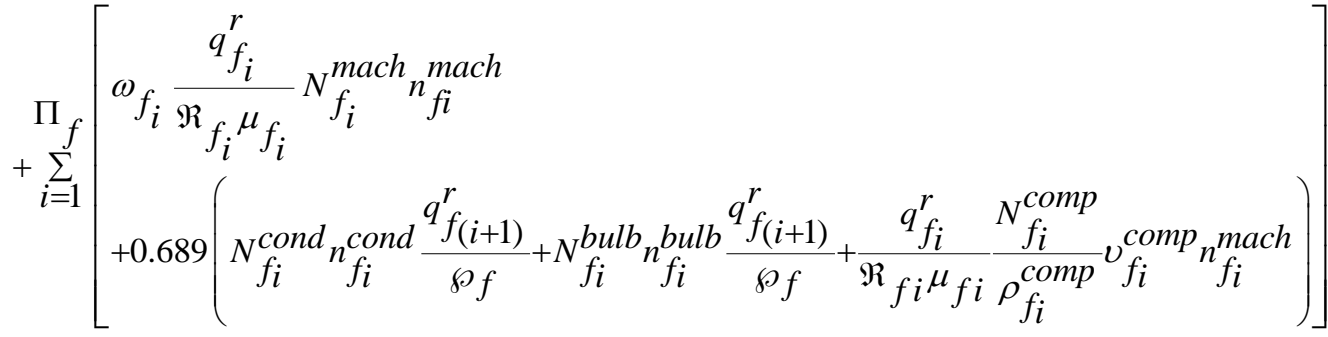$$
+0.689 \sum_{w=1}^{W}\left(N_{w}^{\text {cond }} n_{w}^{\text {cond }} \frac{q_{f w}^{m p}}{\wp_{w}}+N_{w}^{\text {bulb }} n_{w}^{\text {bulb }} \frac{q_{f w}^{m p}}{\wp_{w}}\right)
$$

Where, the $\mathrm{CO}_{2}$ emission factor $\omega_{s_{j}}, \omega_{f_{i}}, \omega_{w}$ and $\omega_{s f}^{t}$ is shown in Table 1 (EPA, 2008; Nujoom et al., 2016b).

Table.1. Amount $\mathrm{CO}_{2}$ emission factor per $\mathrm{kWh}$ and per mile

\begin{tabular}{lcc}
\hline Energy source & $\begin{array}{c}\text { Emission factor } \omega_{s_{j}}, \omega_{f_{i}} \text { and } \omega_{w} \\
(\mathrm{~kg} / \mathrm{kWh})\end{array}$ & $\begin{array}{c}\text { Emission factor } \omega_{s f, f w}^{t} \\
(\mathrm{~kg} / \mathrm{mile})\end{array}$ \\
\hline $\begin{array}{l}\text { Oil as indirect energy source } \\
\text { to generate electricity }\end{array}$ & 0.6895 & 0.420 \\
\hline
\end{tabular}




\section{Constraints}

Equations (48) and (49) ensure that the quantity of raw material shipped to factory $f$ and warehouse $w$ cannot be greater than their capacity.

$q_{s f}^{r} \leq C a_{S}$

$q_{f w}^{m p} \leq \mathrm{Ca} f$

Equations (50) and (51) ensure that the demands of factory $f$ and warehouse $w$ are fulfilled, respectively.

$q_{s f}^{r} \geq D_{f}$

$q_{f w}^{m p} \geq D_{w}$

Equations (52) and (53) ensure that quantity of materials of the first process task $j$ and $i$ must be bigger than or equal to the quantity of materials of the next process task $(j+1)$ and $(i+1)$ in supplier $s$ and factory $f$,

respectively.

$$
\begin{aligned}
& \left(1-\Psi_{s_{j}}\right) q_{s_{j}}^{r} \geq q_{s_{(i+1)}}^{r} \\
& \left(1-\Psi_{f_{i}}\right) q_{f_{(i+1)}}^{r} \geq q_{f_{(i+1)}}^{r}
\end{aligned}
$$

Equations (54) and (.55) are defined that the number of machines involved in process task $j$ in supplier $s$ and process task $i$ in factory $f$ (being served by one air-conditioning unit) must be less than or equal to the number of air-conditioning units involved in this process respectively.

$$
\begin{gathered}
\Phi_{s_{j}}^{\text {cond } n_{s_{j}}^{\text {cond }} \geq n_{s_{j}}^{\text {mach }}} \\
\Phi_{f_{i}}^{\text {cond }} n_{f_{i}}^{\text {cond }} \geq n_{f_{i}}^{\text {mach }}
\end{gathered}
$$

Equations (56) and (57) is defined that the number of light bulbs, which serve all the machines involved in process task $j$ in supplier $s$ and process task $i$ in factory $f$, must be greater than or equal to the number of machines involved in this process respectively.

$$
\begin{aligned}
& n_{s_{j}}^{\text {bulb }} \geq \varphi_{s_{j}}^{\text {bulb }} n_{s_{j}}^{\text {mach }} \\
& n_{f_{i}}^{\text {bulb }} \geq \varphi_{f_{i}}^{\text {bulb }} n_{f_{i}}^{\text {mach }}
\end{aligned}
$$

Equations (58) and (59) are defined as the quantity of products being served by one air-conditioning unit and one lighting bulb in warehouse $w$, respectively. 
$\Gamma_{w}^{c o n d} n_{w}^{\text {cond }} \geq q_{f w}^{m p}$

$\lambda_{w}^{b u l b} n_{w}^{b u l b} \geq q_{f w}^{m p}$

Equation (60) is a non-negativity constraint for the quantity of materials shipped from supplier $s$ to factory $f$ and for products shipped from factory $f$ to warehouse $w$.

$q_{s j}^{r}, q_{s f}^{r}, q_{f_{i}}^{r}, q_{f w}^{m p} \geq 0$

Equations (61) and (62) are defined that the manufacturing rate of process task $j$ and $i$ in supplier $s$ and factory $f$ must be greater than or equal to the quantity of materials involved in the next process task $(j+1)$ and $(i+1)$ in supplier $s$ and factory $f$, respectively.

$$
\begin{aligned}
& \mathfrak{R}_{s_{j}} n_{s_{j}}^{\text {mach }} \geq q_{s_{(i+1)}}^{r} \\
& \mathfrak{R}_{f_{i}} n_{f_{i}^{\text {mach }}} \geq q_{f_{(i+1)}}
\end{aligned}
$$

Where, equations (48), (49), (50), (51), (52), (53) and (60) are quantity constraints; and equations (54)-(59), (61) and (62) are constraints on numbers of machines, air-conditioning units and lighting bulbs.

\section{Optimisation approaches:}

A manufacturing system design towards an optimisation of multiple and possibly conflicting objectives forms a multi-objective optimisation problem. In this case, it is useful to find out an optimum solution for the manufacturing system design with a lowest cost, a lowest amount of energy consumption and $\mathrm{CO}_{2}$ emissions based on the developed multi-objective model. There are several approaches for multi-objective optimization; this includes the $\varepsilon$-constraint method, the weighted-sum method, the LP-metrics method, the weighted tchebycheff method (Nurjanni., et al 2014). In this paper, two approaches are used to gain the optimal solutions, these are the $\varepsilon$-constraint method and the LP-metrics method. Moreover, an optimal solution was determined using the max-min approach.

\subsection{The $\varepsilon$-constraint approach}

In this approach, the multi-objective model is converted into a single-objective aiming to reveal the non-inferior solutions under constraints. The higher priority is given to minimization of the total energy consumption in this study as the single objective function (equation. 63); the other two objective functions (total cost and total $\mathrm{CO}_{2}$ emissions) are shifted to be $\varepsilon$-based constraints; i.e., equation 64 restricts the first objective function to be less than or equal to $\varepsilon_{l}$ between the minimum value and the maximum value for objective function one (equation 65). Equation 66 restricts the third objective function to be less than or equal to $\varepsilon_{2}$ which gradually varies between the minimum value and the maximum value for objective function three (equation 67) (Amin and Zhang, 2013; Mohammed and Wang, 2016). Thus, the equivalent solution formula $\Lambda$ is expressed as follows:

$\operatorname{Min} \Lambda_{2}$

Equation 63 is subject to the following constrains:

$\Lambda_{1} \leq \varepsilon_{1}$

$\left(\Lambda_{1}\right)^{\min } \leq \varepsilon_{1} \leq\left(\Lambda_{1}\right)^{\max }$

$\Lambda_{3} \leq \varepsilon_{2}$ 
$\left(\Lambda_{3}\right)^{\min } \leq \varepsilon_{2} \leq\left(\Lambda_{3}\right)^{\max }$

And additional constraints are included equations 48-62.

\subsection{The LP- metrics approach}

The solution procedure of the LP- metrics method is described as below:

1- Obtain the optimal value for each individual objective by optimizing them individually $\left(\Lambda_{1}^{*}, \Lambda_{2}^{*}\right.$ and $\left.\Lambda_{3}^{*}\right)$

2- Convert the three objectives model into a modular-objective function using the following equation

$$
\operatorname{Min} \Lambda=\left[\mathrm{y}_{1} \frac{\Lambda_{1}-\Lambda_{1}^{*}}{\Lambda_{1}^{*}}+\mathrm{y}_{2} \frac{\Lambda_{2}-\Lambda_{2}^{*}}{\Lambda_{2}^{*}}+\mathrm{y}_{3} \frac{\Lambda_{3}-\Lambda_{3}^{*}}{\Lambda_{3}^{*}}\right]
$$

Subject to equations $48-62$.

3- Determine the importance of each objective function based on decision makers' preferences. The weight formula for the three objective functions is given as below:

$$
\sum_{b=1}^{3} y_{b}, \text { where } \mathrm{y}_{b} \geq 0(b=1,2,3)
$$

$$
\operatorname{Min} \Lambda=\left(\sum_{a=1}^{3} l_{a}\left|\Lambda_{a}-\Lambda_{a}^{*}\right|^{p}\right)^{\frac{1}{p}}
$$

Subject to equations 48-62. It is noticed that the values of the objective functions are dependent on the value of $p$. usually, the value of $p$ is either 1 or 2 . In this work the value of $p$ is set as 1 .

\subsection{The Max-Min approach}

The Max-Min approach is normally applied for selecting the compromised solution $x$ in a non-inferior set based on the objective function $\Lambda$ using a satisfaction value $\vartheta_{\Lambda_{x}}$. For further details about this approach, it may refer to Lai and Hwang, 1992). The Max-Min approach formula is described as follows:

$$
\begin{gathered}
\operatorname{Max}_{x}\left\{\min \left\{\vartheta_{\Lambda_{x}}-\vartheta_{\Lambda_{x}}^{r e f}\right\}\right\} \\
=\operatorname{Max}_{x}\left\{\operatorname { m i n } \left\{\left(\frac{\Lambda_{x}^{\max }-\Lambda(x)}{\left.\left.\left.\Lambda_{x}^{\max }-\Lambda_{x}^{\min }\right)-\vartheta_{\Lambda_{x}}^{r e f}\right\}\right\}}\right.\right.\right. \\
\text { s.t. }\left\{\vartheta_{\Lambda_{x}}= \begin{cases}1 \frac{\Lambda_{x}^{\max }-\Lambda(x)}{\left.\Lambda_{x}^{\max }-\Lambda_{x}^{\min }\right)} & \Lambda_{x}^{\min } \leq \Lambda(x) \leq \Lambda_{x}^{\max } \\
0 & \Lambda(x) \geq \Lambda_{x}^{\max }\end{cases} \right.
\end{gathered}
$$

Where, $\Lambda_{x}^{\max }$ is the maximum value and $\Lambda_{x}^{\min }$ is the minimum value, which are obtained based on the objective function $\Lambda_{x}$, respectively. In the non-inferior set, $\vartheta_{\Lambda_{x}}^{\text {ref }}$ is a minimal accepted satisfaction value for objective function $\Lambda_{x}$ which is assigned by manufacturing designers in consonance to their needs.

\section{Application and evaluation}


In this section, a case study was used for the applicability of the developed models and the proposed optimisation methods as described above. The study was carried out for analysing the total cost for establishing the facilities (supplier $s$, factory $f$ and warehouse $w$ ), the energy consumption and the amount of $\mathrm{CO}_{2}$ emissions towards a sustainable manufacturing design. Table 2 shows the manufacturing process with the symbols representing each task of a manufacturing process for the production of plastic and woven sacks inside supplier $s$ and factory $f$. Table 3 shows the relevant parameters and their values used for the case study, it includes 1 supplier, 1 factory and 1 warehouse. All the parameters were taken from a real manufacturing system, which produces plastic and woven sacks. In this case, the production line is powered by electricity which is generated using oil as source of energy. IINGO $^{11}$ was used for computing results aiming to seek the optimization solutions.

Table. 2. Manufacturing processes tasks for producing plastic and woven sacks

\begin{tabular}{lll}
\hline Tasks & Description & predecessors \\
\hline A & Gas-phase & None \\
B & Converted the gas to liquid & A \\
D & Converted the liquid to powder & B \\
H & Converted powder to pellets & D \\
R.M & Raw material (polypropylene) & G \\
G & Extruding the Polypropylene to make stands & R.M \\
W & Weaving the stands into rolls of sacks & K \\
L & Laminating the rolls & H \\
P & Printing and branding & L \\
C & Cutting the rolls into bags & P \\
K & Inserts and smoothest out blown film into the bags & C \\
S & Blown film is sewn into bag & M \\
Z & End product compressed & Y \\
W & Store the products in warehouse & $\mathrm{Z}$ \\
\hline
\end{tabular}

Tabl.3. Data collected from a plastic and woven sacks company

\begin{tabular}{|c|c|c|}
\hline \multicolumn{3}{|c|}{ Facilities } \\
\hline Supplier $s$ & Factory $f$ & Warehouse $w$ \\
\hline$C_{S}^{e S}(\mathrm{GBP}): 100000$ & $C_{f}^{e s}$ (GBP): 100000 & $C_{w}^{e s}(\mathrm{GBP}): 55000$ \\
\hline $\begin{array}{l}C_{s_{j}}^{m a c h}(\mathrm{GBP}): 7000,7000,7000, \\
7000, \text { where } j \in\left\{1,2, \ldots ., \Pi_{s}\right\}\end{array}$ & $\begin{array}{l}C_{f_{i}}^{m a c h}(\mathrm{GBP}): 5000,3000,4000, \\
3000,3000,100,200,2000, \text { where } \\
i \in\left\{1,2, \ldots ., \Pi_{f}\right\}\end{array}$ & -------------- \\
\hline $\begin{array}{l}C_{s_{j}}^{c o n d}(\mathrm{GBP}): 1000,1000,1000, \\
1000\end{array}$ & $\begin{array}{l}C_{f_{i}}^{\text {cond }}(\mathrm{GBP}): 1000,1000,1000 \\
1000,1000,1000,1000,1000\end{array}$ & $C_{w}^{c o n d}(\mathrm{GBP}): 700$ \\
\hline$C_{s_{j}}^{b u l p}$ (GBP): 50, 50, 50, 50 & $\begin{array}{l}C_{f_{i}}^{b u l p}(\mathrm{GBP}): 50,50,50,50,50, \\
50,50,50\end{array}$ & $C_{w}^{b u l b}(\mathrm{GBP}): 50$ \\
\hline$C_{S}^{r}(\mathrm{GBP} / \mathrm{kg}): 2$ & $C_{f}^{m p}(\mathrm{GBP} / \mathrm{kg}): 3$ & $C_{w}^{I}(\mathrm{GBP} / \mathrm{kg}): 2$ \\
\hline$C_{s f}^{t}(\mathrm{GBP} / \mathrm{mile}): 2$ & $C_{f w}^{t}(\mathrm{GBP} / \mathrm{mile}): 2$ & ------------- \\
\hline$T_{s f}$ (mile): $50, V(\mathrm{~kg}): 20000$ & $T_{f w}($ mile $): 10, V=20000$ & ------------- \\
\hline$C a_{s}$ (kg/month): 1000000 & $C a_{f}$ (kg/month): 990,000 & $C a_{w}(\mathrm{~kg} / \mathrm{month}): 900000$ \\
\hline ----- & $D_{f}(\mathrm{~kg} / \mathrm{month}): 850000$ & $D_{w}(\mathrm{~kg} / \mathrm{month}): 850000$ \\
\hline
\end{tabular}




\begin{tabular}{|c|c|c|}
\hline$\Pi_{S}=4$ process & $\Pi_{f}=8$ process & ------------- \\
\hline $\begin{array}{l}\mathfrak{R}_{s_{j}}(\mathrm{~kg} / \mathrm{h}): 1976,1936,1932 \text { and } \\
1929, \text { where } j \in\left\{1,2, \ldots ., \Pi_{s}\right\}\end{array}$ & $\begin{array}{l}\mathfrak{R}_{f_{i}}(\mathrm{~kg} / \mathrm{h}): 1852,1815,1742, \\
1716,1699,1665,1660 \text { and 1643, } \\
\text { where } i \in\left\{1,2, \ldots ., \Pi_{f}\right\}\end{array}$ & ------------- \\
\hline$\mu_{s_{j}}(\%): 80$ for all machines & $\mu_{f_{i}}(\%): 80$ for all machines & ------------- \\
\hline$\Psi_{s_{j}}(\%): 0.03,0.02,0.002,0.15$ & $\begin{array}{l}\Psi_{f_{i}}(\%): 0.02,0.04,0.015,0.01, \\
0.02,0.003,0.01,0\end{array}$ & ------------- \\
\hline$N_{s_{j}}^{\text {mach }}(\mathrm{kw}): 700,500,300,600$ & $\begin{array}{l}N_{f_{i}}^{m a c h}(\mathrm{kw}): 200,20,7,40,7,0, \\
0.8,4\end{array}$ & ------------- \\
\hline$N_{s_{j}}^{c o m p}(\mathrm{kw}): 0$ & $N_{f_{i}}^{c o m p}(\mathrm{kw}): 200$ & ------------- \\
\hline$\rho_{s_{j}}^{\operatorname{comp}}\left(\mathrm{m}^{3} / \mathrm{h}\right): 0$ & $\rho_{f_{i}}^{c o m p}\left(\mathrm{~m}^{3} / \mathrm{h}\right): 666$ & ------------- \\
\hline$v_{s_{j}}^{\operatorname{comp}}\left(\mathrm{m}^{3} / \mathrm{h}\right): 0$ & $\begin{array}{l}v_{f_{i}}^{\operatorname{comp}}\left(\mathrm{m}^{3} / \mathrm{h}\right): 5,4,13,0,7,5,20, \\
0,0,0\end{array}$ & ------------- \\
\hline$N_{s_{j}}^{\text {cond }}(\mathrm{kw}): 3.5$ & $N_{f_{i}}^{\text {cond }}(\mathrm{kw}): 3.5$ & $N_{w}^{\text {cond }}(\mathrm{kw}): 3.5$ \\
\hline$N_{s_{j}}^{b u l b}(\mathrm{kw}): 2.5$ & $N_{f_{i}}^{b u l b}(\mathrm{kw}): 2.5$ & $N_{w}^{b u l b}(\mathrm{kw}): 2.5$ \\
\hline $\begin{array}{l}\Phi_{s_{j}}^{c o n d} \text { (units): } 2, \varphi_{s_{j}}^{b u l b} \text { (units): } \\
15\end{array}$ & $\Phi_{f_{i}}^{\text {cond }}$ (units): $2, \varphi_{f_{i}}^{b u l b}$ (units): 15 & $\begin{array}{ll}\Gamma_{w}^{c o n d} & (\mathrm{~kg}): 1000, \\
500\end{array}$ \\
\hline$\wp_{s}(\mathrm{~kg}): 950000$ & $\wp_{f}(\mathrm{~kg}): 840000$ & $\wp_{w}$ (units): $9,032,258$ \\
\hline$\omega_{s_{j}}(\mathrm{~kg} / \mathrm{kWh}): 0.6895$ & $\omega_{f_{i}}(\mathrm{~kg} / \mathrm{kWh}): 0.6895$ & $\omega_{w}(\mathrm{~kg} / \mathrm{kWh}): 0.6895$ \\
\hline$\omega_{s f}^{t}(\mathrm{~kg} / \mathrm{mile}): 0.420$ & $\omega_{f w}^{t}(\mathrm{~kg} / \mathrm{mile}): 0.420$ & ------------- \\
\hline
\end{tabular}

\subsection{Computational results and discussion}

Table 4 shows the solution results obtained using the $\varepsilon$-constraint approach; this includes eight epsilon values by assigning the incremental value of $\varepsilon$ from $23,239,639$ to $30,990,000$ based on objective one and from $17.9 \times 10^{9}$ to $20.4 \times 10^{9}$ based on objective three. Table 5 shows the solution results using the LP-metrics method in which each objective was optimized individually to obtain the ideal value. As shown in Table 4, solution 1, as an example, was obtained by assigning $\varepsilon_{1}=23,239,639$ and $\varepsilon_{2}=17.9 \times 10^{9}$, respectively; it gives the minimum total cost of 23,239,639 GBP, the minimum total amount of energy of 2,842,852 kWh and the minimum total amount of $\mathrm{CO}_{2}$ emissions of $17.9 \times 10^{9} \mathrm{~kg}$. 
Table 4. The non-inferior solutions obtained by using the $\varepsilon$-constraint approach

\begin{tabular}{|c|c|c|c|c|c|}
\hline \multirow{2}{*}{$\begin{array}{c}\text { Solution } \\
\text { number }\end{array}$} & \multicolumn{2}{|c|}{ Assigned $\boldsymbol{E}$ values } & \multicolumn{3}{c|}{ Objective function solutions } \\
\cline { 2 - 6 } & $\varepsilon_{1}$ & $\varepsilon_{2}$ & $\begin{array}{c}\operatorname{Min} \Lambda_{1} \\
(\text { Cost }) \\
(\mathrm{GBP})\end{array}$ & $\begin{array}{c}\operatorname{Min} \Lambda_{2} \\
(\text { Energy }) \\
(\mathrm{kWh} / \mathrm{month})\end{array}$ & $\begin{array}{c}\operatorname{Min} \Lambda_{3} \\
\left(\mathrm{CO}_{2}\right) \\
(\mathrm{kg} / \mathrm{month})\end{array}$ \\
\hline $\mathbf{1}$ & $23,239,639$ & $17.9 \times 10^{9}$ & $23,239,639$ & $2,842,852$ & $17.9 \times 10^{9}$ \\
\hline $\mathbf{2}$ & $24,808,211$ & $18.35 \times 10^{9}$ & $24,640,700$ & $3,128,510$ & $18.3 \times 10^{9}$ \\
\hline $\mathbf{3}$ & $26,150,354$ & $18.66 \times 10^{9}$ & $26,000,000$ & $3,414,168$ & $18.6 \times 10^{9}$ \\
\hline $\mathbf{4}$ & $27,492,497$ & $18.9 \times 10^{9}$ & $27,370,000$ & $3,699,826$ & $18.9 \times 10^{9}$ \\
\hline $\mathbf{5}$ & $28,800,000$ & $19.5 \times 10^{9}$ & $28,800,000$ & $3,998,500$ & $19.4 \times 10^{9}$ \\
\hline $\mathbf{6}$ & $29,990,000$ & $19.75 \times 10^{9}$ & $29,600,000$ & $4,200,000$ & $19.7 \times 10^{9}$ \\
\hline $\mathbf{7}$ & $30,895,000$ & $20.2 \times 10^{9}$ & $30,550,000$ & $4,450,000$ & $20.1 \times 10^{9}$ \\
\hline $\mathbf{8}$ & $30,990,000$ & $20.4 \times 10^{9}$ & $30,990,000$ & $4,820,000$ & $20.4 \times 10^{9}$ \\
\hline
\end{tabular}

By comparison as shown in Table 4, solution 1 was obtained using the LP-metrics approach by assigning $\mathrm{y}_{1}=1$, $\mathrm{y}_{2}=0$ and $\mathrm{y}_{3}=0$; it gives the minimum total cost of 23,365,022 GBP, the minimum total amount of energy of $3,335,765 \mathrm{kWh}$ and the minimum total amount of $\mathrm{CO}_{2}$ emissions of $18.2 \times 10^{9} \mathrm{~kg}$.

Table 5. Non-inferior solutions obtained using the LP-metrics approach

\begin{tabular}{|c|c|c|c|c|c|c|}
\hline \multirow{2}{*}{$\begin{array}{c}\text { Solution } \\
\text { number }\end{array}$} & \multicolumn{3}{|c|}{ Objectives weights } & \multicolumn{3}{c|}{ Objective function solutions } \\
\cline { 2 - 7 } & $\mathrm{y}_{1}$ & $\mathrm{y}_{2}$ & $\mathrm{y}_{3}$ & $\begin{array}{c}\operatorname{Min} \Lambda_{1}(\mathrm{Cost}) \\
(\mathrm{GBP})\end{array}$ & $\begin{array}{c}\text { Min } \Lambda_{2} \\
(\text { Energy })\end{array}$ & $\begin{array}{c}\operatorname{Min} \Lambda_{3} \\
\left(\mathrm{CO}_{2}\right) \\
(\mathrm{kWh} / \mathrm{month})\end{array}$ \\
\hline $\mathbf{1}$ & 0 & 1 & 0 & $23,365,022$ & $3,335,765$ & $18.2 \times 10^{9}$ \\
\hline $\mathbf{2}$ & 0.05 & 0.9 & 0.05 & $24,788,014$ & $3,640,480$ & $18.5 \times 10^{9}$ \\
\hline $\mathbf{3}$ & 0.1 & 0.8 & 0.1 & $26,200,100$ & $3,960,210$ & $18.8 \times 10^{9}$ \\
\hline $\mathbf{4}$ & 0.15 & 0.7 & 0.15 & $27,500,088$ & $4,299,935$ & $19 \times 10^{9}$ \\
\hline $\mathbf{5}$ & 0.2 & 0.6 & 0.2 & $28,848,050$ & $4,489,654$ & $19.5 \times 10^{9}$ \\
\hline $\mathbf{6}$ & 0.25 & 0.5 & 0.25 & $29,690,000$ & $4,950,000$ & $19.8 \times 10^{9}$ \\
\hline $\mathbf{7}$ & 0.3 & 0.4 & 0.3 & $30,590,000$ & $5,380,000$ & $20.3 \times 10^{9}$ \\
\hline $\mathbf{8}$ & 0.35 & 0.3 & 0.35 & $31,000,000$ & $5,750,000$ & $20.8 \times 10^{9}$ \\
\hline
\end{tabular}

Tables 6, 7, 8 and 9 show the obtained solutions that contain potential groups in numbers of machines, air conditioning units and lighting bulbs that should be established in the sustainable manufacturing system. These solutions were obtained using the $\varepsilon$-constraint approach and the LP-metrics approach, respectively. For instance, Table 6 shows the result for solution 1 using the $\varepsilon$-constraint approach which gives the group in numbers of machines involved in process $j$ in supplier $s_{\left(n_{s_{j}} \text { mach }\right.}$ ) where $j \in\{1,2,3,4\}$ is $(2,2,1,1)$, the group in numbers of air conditioning units $\left(n_{s_{j}}^{\text {cond }}\right)$ is $(1,1,1,1)$ and the group in numbers of lighting bulbs $\left(n_{s}^{b u l b}\right)$ is $(30,30,15$, 15). Table 7 shows the result for solution 1 using the $\varepsilon$-constraint approach which gives the group in numbers of machines involved in process $i$ in factory $\left.f_{\left(n_{f_{i}}\right.}^{\text {mach }}\right)$ where $i \in\{1,2,3,4,5,6,7,8\}$ is $(4,40,3,5,13,13$, $60,4)$, the group in numbers of air conditioning units involved in process $i_{\left(n_{f_{i}}^{\text {cond }}\right)}$ is $(2,20,2,3,7,7,30,2)$ and the group in numbers of lighting bulbs $\left(n_{f_{i}}^{b u l b}\right)$ is $(60,600,45,75,195,195,900,60)$. Table 7 also shows that solution 1 requires 832 air conditioning units $\left(n_{w}^{c o n d}\right)$ and 1664 lighting bulbs $\left(n_{w}^{b u l b}\right)$ that need to be installed in warehouse $w$. 
Table 6. Numbers of machines, air conditioning units and bulbs involved in process $j$ in supplier $s$ under the $\varepsilon^{-}$ constraint approach

\begin{tabular}{|c|c|c|c|c|c|c|c|c|c|c|c|c|}
\hline \multirow[t]{2}{*}{$\begin{array}{l}\text { Solution } \\
\text { Number }\end{array}$} & \multicolumn{4}{|c|}{$\begin{array}{l}\text { Numbers of machines } \\
\text { involved in process } j, \\
\qquad n_{s} \text { mach } \\
\text { Where } j \in\{1,2,3,4\} .\end{array}$} & \multicolumn{4}{|c|}{$\begin{array}{c}\text { Numbers of air- } \\
\text { conditioning units } \\
\text { involved in process } j \\
n_{s_{j}}^{\text {cond }} \\
\text { Where } j \in\{1,2,3,4\} .\end{array}$} & \multicolumn{4}{|c|}{$\begin{array}{c}\text { Numbers of bulbs } \\
\text { involved in process } j \\
\qquad \begin{array}{c}\text { bulb } \\
n_{j}\end{array} \\
\text { Where } j \in\{1,2,3,4\} .\end{array}$} \\
\hline & $n_{s l}$ & $n_{s 2}$ & $n_{s 3}$ & $n_{s 4}$ & $n_{s 1}$ & $n_{s 2}$ & $n_{s 3}$ & $n_{s 4}$ & $n_{s l}$ & $n_{s 2}$ & $n_{s 3}$ & $n_{s 4}$ \\
\hline 1 & 2 & 2 & 1 & 1 & 1 & 1 & 1 & 1 & 30 & 30 & 15 & 15 \\
\hline 2 & 2 & 2 & 2 & 1 & 1 & 1 & 1 & 1 & 30 & 30 & 30 & 30 \\
\hline 3 & 2 & 2 & 2 & 2 & 1 & 1 & 1 & 1 & 30 & 30 & 30 & 30 \\
\hline 4 & 2 & 2 & 2 & 2 & 1 & 1 & 1 & 1 & 30 & 30 & 30 & 30 \\
\hline 5 & 2 & 2 & 2 & 2 & 1 & 1 & 1 & 1 & 30 & 30 & 30 & 30 \\
\hline 6 & 3 & 3 & 3 & 3 & 2 & 2 & 2 & 2 & 45 & 45 & 45 & 45 \\
\hline 7 & 3 & 3 & 3 & 3 & 2 & 2 & 2 & 2 & 45 & 45 & 45 & 45 \\
\hline 8 & 3 & 3 & 3 & 3 & 2 & 2 & 2 & 2 & 45 & 45 & 45 & 45 \\
\hline
\end{tabular}

Table 7. Numbers of machines, air conditioning units and bulbs involved in process $i$ in factory $f$ and warehouse $w$ under the $\varepsilon$-constraint approach

\begin{tabular}{|c|c|c|c|c|c|c|c|c|c|c|c|}
\hline$\infty$ & $\checkmark$ & $a$ & $u$ & 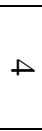 & $\omega$ & $N$ & - & & 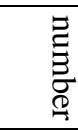 & 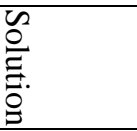 & \\
\hline$a$ & $a$ & $a$ & ur & $u$ & ur & ur & $A$ & 尽 & \multirow{12}{*}{ 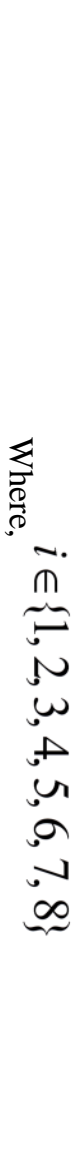 } & \multirow{8}{*}{$\rightarrow \frac{2}{3}$} & \multirow{8}{*}{ 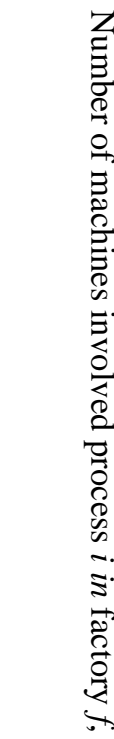 } \\
\hline z̆ & ğ & $u^{\prime}$ & y' & y & $\stackrel{\Delta}{u}$ & $b$ & $t$ & 㤀 & & & \\
\hline$\checkmark$ & $a$ & $a$ & $a$ & $a$ & $u$ & 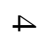 & $\omega$ & $\stackrel{s}{s}$ & & & \\
\hline 0 & $\infty$ & $\infty$ & $\checkmark$ & $a$ & $a$ & ur & ur & 5 & & & \\
\hline$\vec{\infty}$ & $\vec{\infty}$ & $\Xi$ & $\Xi$ & $\vec{a}$ & $\vec{a}$ & $\vec{A}$ & $\bar{\omega}$ & $\xi$ & & & \\
\hline$\vec{\infty}$ & $\bar{\infty}$ & $\Xi$ & $\Xi$ & $\vec{a}$ & $\vec{a}$ & $\vec{A}$ & $\bar{\omega}$ & F & & & \\
\hline ஓे & 9 & 9 & $\hat{~ \hat{~}}$ & $\hat{~ i n}$ & bे & aे & gे & 疋 & & & \\
\hline$v$ & $\checkmark$ & $a$ & $a$ & ur & ur & $\triangle$ & $A$ & F్ & & & \\
\hline$\omega$ & $\omega$ & $\omega$ & $\omega$ & $\omega$ & $\omega$ & $\omega$ & $N$ & $\$$ & & & 壳. \\
\hline$\infty$ & $\infty$ & $\infty$ & N & N & 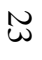 & 응 & $\widetilde{N}$ & 思 & & & \\
\hline 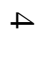 & $\omega$ & $\omega$ & $\omega$ & $\omega$ & $\omega$ & $N$ & $N$ & $\mathcal{S}$ & & & - \\
\hline$u$ & $\Delta$ & 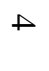 & 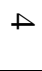 & $\omega$ & $\omega$ & $\omega$ & $\omega$ & $F$ & & & ङ: \\
\hline
\end{tabular}




\begin{tabular}{|c|c|c|c|c|c|c|c|c|c|c|c|}
\hline 0 & 0 & 0 & 0 & $\infty$ & $\infty$ & $v$ & $v$ & 忌 & & & \\
\hline 0 & 0 & 0 & 0 & $\infty$ & $\infty$ & $v$ & $v$ & F & & & \\
\hline$\underset{\not}{\omega}$ & $\stackrel{w}{\not}$ & $\underset{\not}{\omega}$ & $\underset{\omega}{w}$ & $\underset{\omega}{\omega}$ & $\ddot{\sigma}$ & w & $\stackrel{w}{\sigma}$ & 点 & & & \\
\hline 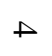 & $\Delta$ & $\omega$ & $\omega$ & $\omega$ & $\omega$ & $N$ & $N$ & $\stackrel{\Xi}{~}$ & & & \\
\hline 8 & 8 & 8 & $\vec{u}$ & $\vec{u}$ & $u$ & $\vec{u}$ & 8 & $\$$ & & \multirow{8}{*}{ 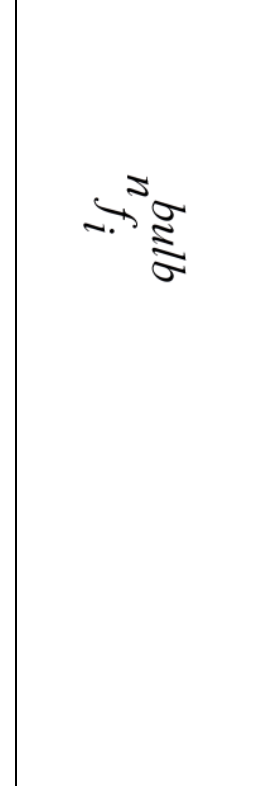 } & \multirow{8}{*}{ 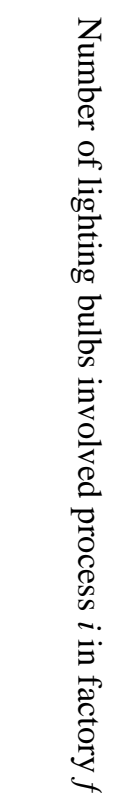 } \\
\hline $\begin{array}{l}\infty \\
\stackrel{\Delta}{0}\end{array}$ & $\begin{array}{l}\infty \\
\stackrel{1}{0}\end{array}$ & 忍 & प̆ & प̆ & जे & छे & छे & 胥 & & & \\
\hline$\vec{u}$ & 8 & 8 & 8 & ঃ & $\dot{u}$ & 8 & ur & $\mathcal{F}$ & & & \\
\hline$\breve{u}_{u}$ & $\bar{N}$ & $\overline{\tilde{O}}$ & $\vec{u}$ & ๑ & ๖ & $\vec{u}$ & $\vec{u}$ & 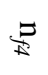 & & & \\
\hline N & N & 录 & $\tilde{u}$ & $\begin{array}{l}N \\
0\end{array}$ & $\stackrel{N}{\Delta}$ & $\frac{N}{0}$ & $\vec{b}$ & 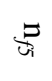 & & & \\
\hline$\stackrel{N}{0}$ & $\stackrel{N}{0}$ & 崩 & $\mathcal{N}^{N}$ & $\stackrel{N}{0}$ & $\stackrel{N}{0}$ & $\frac{N}{\sigma}$ & 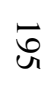 & F & & & \\
\hline 尽 & $\overrightarrow{8}$ & 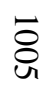 & ư & 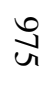 & 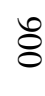 & 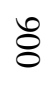 & 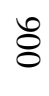 & 守 & & & \\
\hline$\vec{e}$ & $\vec{s}$ & 8 & 8 & $\vec{u}$ & $\bar{u}$ & 8 & 8 & $\underset{\infty}{F}$ & & & \\
\hline $\begin{array}{l}\infty \\
\infty \\
\infty\end{array}$ & $\stackrel{\infty}{\varrho}$ & $\begin{array}{l}\text { ఎ } \\
\infty\end{array}$ & $\begin{array}{l}\infty \\
\infty\end{array}$ & $\begin{array}{l}\infty \\
\infty\end{array}$ & $\stackrel{\infty}{\sim}$ & 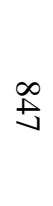 & $\underset{\sim}{\infty}$ & & 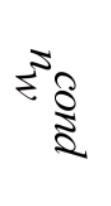 & 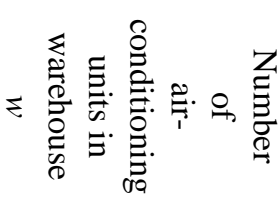 & \\
\hline$\vec{a}$ & $\vec{N}$ & $\begin{array}{l}\vec{u} \\
\vec{u}\end{array}$ & ন্র & $\vec{N}$ & $\overrightarrow{\mathbb{N}}$ & बे & $\bar{a}$ & & $\sum_{\vdots}^{\Xi}$ & 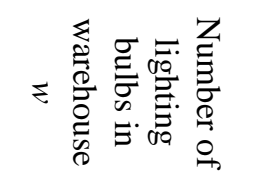 & \\
\hline
\end{tabular}

Table 8 shows the obtained results of solution 1-8 using the LP-metrics approach. For instance, solution 1 gives the group $(2,2,2,1)$ in numbers of machines, which should be involved in process $j$ in supplier $\left.s_{\left(n_{s}\right.}^{\text {mach }}\right)_{j}$ where $j \in\{1,2,3,4\}$; the group $(1,1,1,1)$ in numbers of air conditioning units $\left.{ }_{\left(n_{s}\right.}^{\text {cond }}{ }_{j}\right)$ and the group $(30,30,30$, 15) in numbers of lighting bulbs $\left(n_{s_{j}}^{b u l b}\right)$. Table 9 shows the result for solution 1 using the LP-metrics approach which gives the group in numbers of machines that should be involved in process $i$ in factory $f_{\left(n_{f_{i}}\right.}^{\text {mach })}$ where $i \in\{1,2,3,4,5,6,7,8\}$ is $(4,45,4,5,14,14,60,4)$, the group in numbers of air conditioning units $\left(n_{f_{i}}^{\text {cond }}\right)$ is $(2$, $23,2,3,7,7,30,2)$ and the group in numbers of lighting bulbs $\left(n_{f_{i}}^{b u l b}\right)$ is $(60,675,60,75,210,210,900,60)$. Solution 1 also gives 832 air conditioning units $\left(n_{w}^{\text {cond }}\right)$ and 1664 lighting bulbs $\left(n_{w}^{b u l b}\right)$ installed in warehouse $w$ 
Table. 8 Solutions in numbers of machines, air conditioning units and bulbs involved in process $i$ in supplier $s$ based on LP-metrics approach

\begin{tabular}{|c|c|c|c|c|c|c|c|c|c|c|c|c|}
\hline \multirow[t]{2}{*}{$\begin{array}{c}\text { Solution } \\
\text { number }\end{array}$} & \multicolumn{4}{|c|}{$\begin{array}{l}\text { Numbers of machines } \\
\text { involved in process } j, \\
\qquad n_{s_{j}}^{\text {mach }} \\
\text { Where } j \in\{1,2,3,4\} .\end{array}$} & \multicolumn{4}{|c|}{$\begin{array}{l}\text { Numbers of air conditioning } \\
\text { units involved in process } j \\
\qquad n_{s_{j}}^{\text {cond }} \\
\text { Where } j \in\{1,2,3,4\} .\end{array}$} & \multicolumn{4}{|c|}{$\begin{array}{c}\begin{array}{c}\text { Numbers of bulbs } \\
\text { involved in process } j \\
\text { bulb } \\
n_{s_{j}}\end{array} \\
\text { Where } j \in\{1,2,3,4\} .\end{array}$} \\
\hline & $n_{s 1}$ & $n_{s 2}$ & $n_{s 3}$ & $n_{s 4}$ & $n_{s 1}$ & $n_{s 2}$ & $n_{s 3}$ & $n_{s 4}$ & $n_{s l}$ & $n_{s 2}$ & $n_{s 3}$ & $n_{s 4}$ \\
\hline 1 & 2 & 2 & 2 & 1 & 1 & 1 & 1 & 1 & 30 & 30 & 30 & 15 \\
\hline 2 & 2 & 2 & 2 & 2 & 1 & 1 & 1 & 1 & 30 & 30 & 30 & 30 \\
\hline 3 & 2 & 2 & 2 & 2 & 1 & 1 & 1 & 1 & 30 & 30 & 30 & 30 \\
\hline 4 & 2 & 2 & 2 & 2 & 1 & 1 & 1 & 1 & 30 & 30 & 30 & 30 \\
\hline 5 & 3 & 3 & 3 & 3 & 2 & 2 & 2 & 2 & 45 & 45 & 45 & 45 \\
\hline 6 & 3 & 3 & 3 & 3 & 2 & 2 & 2 & 2 & 45 & 45 & 45 & 45 \\
\hline 7 & 3 & 3 & 3 & 3 & 2 & 2 & 2 & 2 & 45 & 45 & 45 & 45 \\
\hline 8 & 3 & 3 & 3 & 3 & 2 & 2 & 2 & 2 & 45 & 45 & 45 & 45 \\
\hline
\end{tabular}

Table. 9 Solutions in numbers of machines, air conditioning units and bulbs involved in process $i$ in factory $f$ and warehouse $w$ under the LP-metrics approach

\begin{tabular}{|c|c|c|c|c|c|c|c|c|c|c|c|}
\hline$\infty$ & $v$ & $a$ & $u$ & 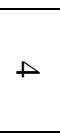 & $\omega$ & $N$ & - & & $\begin{array}{l}\overrightarrow{0} \\
\stackrel{0}{0} \\
\stackrel{\Phi}{9}\end{array}$ & है & \\
\hline$\checkmark$ & $\checkmark$ & $\checkmark$ & $\checkmark$ & $a$ & $a$ & $a$ & $A$ & $\$$ & \multirow{12}{*}{ 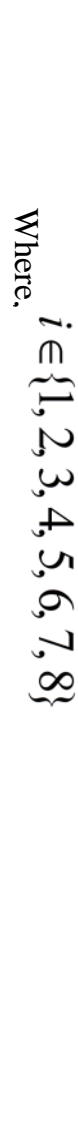 } & \multirow{8}{*}{$\begin{array}{r}\frac{5}{3} \\
-\pi \frac{5}{3}\end{array}$} & \multirow{8}{*}{ 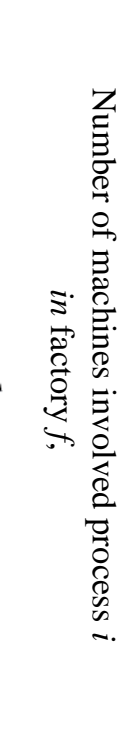 } \\
\hline Й & ֵ̆ & $u$ & Uू & y̆ & 它 & ur & 它 & 志 & & & \\
\hline$\checkmark$ & $v$ & $\checkmark$ & $\checkmark$ & $a$ & $u$ & 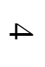 & A & $\stackrel{F}{\omega}$ & & & \\
\hline 6 & $\infty$ & $\infty$ & $v$ & $a$ & $a$ & ur & ur & $\$$ & & & \\
\hline 6 & $\vec{\infty}$ & $\Xi$ & $\Xi$ & $\bar{a}$ & $\bar{a}$ & $\vec{A}$ & $\vec{A}$ & s & & & \\
\hline$\sigma$ & $\infty$ & $\nabla$ & $\Xi$ & $\vec{a}$ & $\bar{\sigma}$ & $\vec{A}$ & $\Phi$ & $\mathcal{F}$ & & & \\
\hline$\infty$ & 9 & 9 & जे & जे & aे & oे & aे & ร & & & \\
\hline$v$ & $v$ & $a$ & $a$ & $u$ & ur & 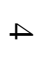 & A & $\mathscr{\wp}$ & & & \\
\hline 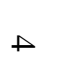 & $A$ & $A$ & 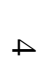 & $\omega$ & $\omega$ & $\omega$ & $N$ & $\$$ & & \multirow{4}{*}{\multicolumn{2}{|c|}{ 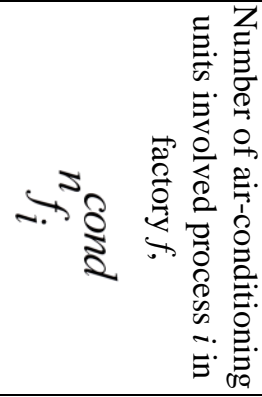 }} \\
\hline $\mathbb{\infty}$ & $\infty$ & $\mathbb{\infty}$ & $\stackrel{\sim}{u}$ & $\tilde{u}$ & $\stackrel{\sim}{\omega}$ & N & $\tilde{\omega}$ & 志 & & & \\
\hline 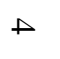 & $A$ & $A$ & 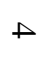 & $\omega$ & $\omega$ & $N$ & $N$ & $\mathcal{E}$ & & & \\
\hline ur & $A$ & $A$ & $A$ & $\omega$ & $\omega$ & $\omega$ & $\omega$ & 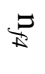 & & & \\
\hline
\end{tabular}




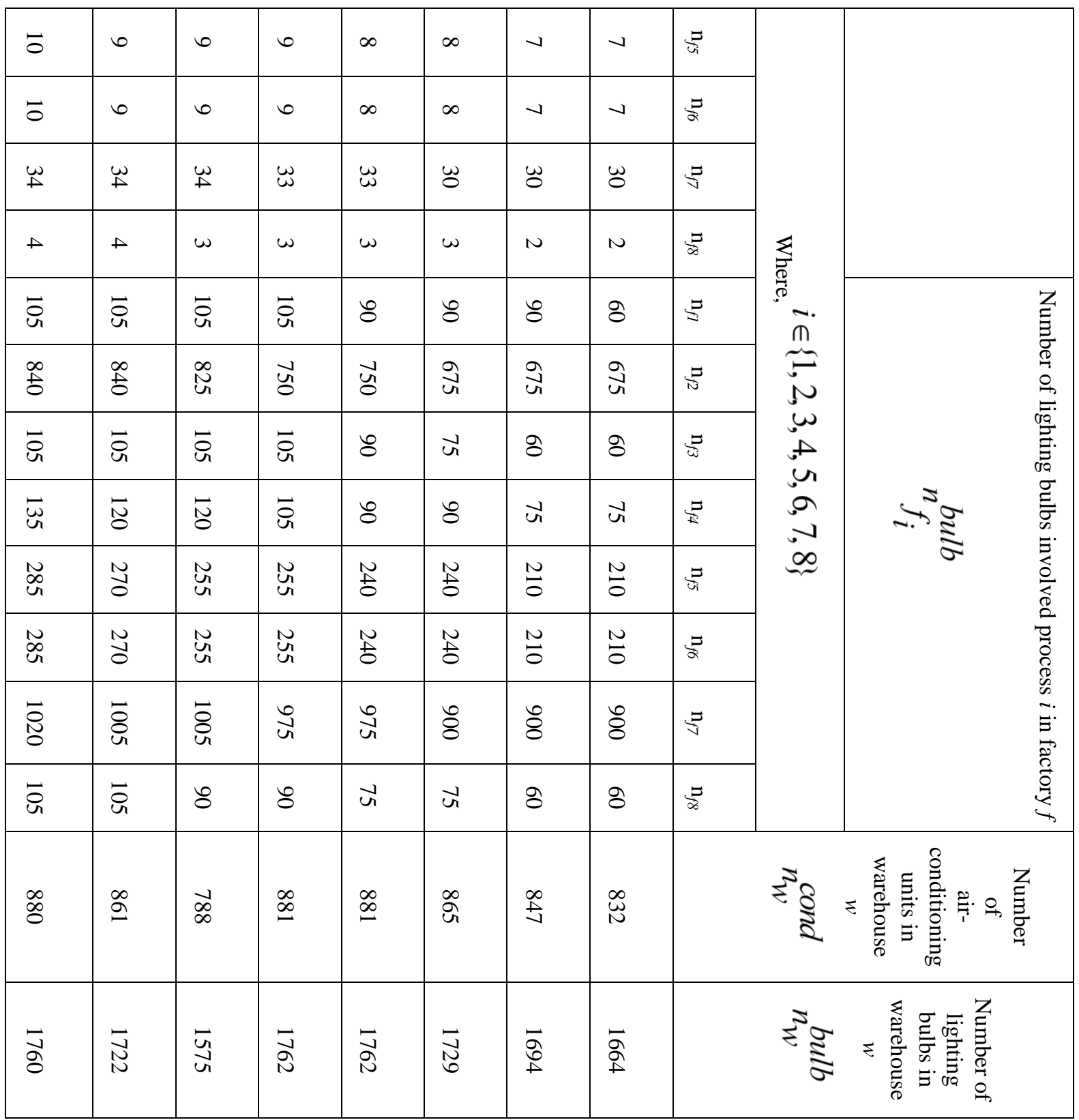

Figures $2 \mathrm{a}, 2 \mathrm{~b}$ and $2 \mathrm{c}$ illustrate a pairwise comparison in a relationship between two of the three conflicting objectives. Arguably, the two approaches performed well in generating the non-inferior solutions. However, the results shown in figures $2 \mathrm{a}$ and $2 \mathrm{~b}$ indicate that the non-inferior solutions obtained using the $\varepsilon$-constraint approach; it gives values of the total cost and the total energy consumption less than those of the non-inferior solutions obtained using the LP-metrics approach. For instance, they indicate that the minimum total cost for establishing the manufacturing system under solution 1 using $\varepsilon$-constraint approach is 23,239,639 GBP which is less than the minimum total cost under the LP-metrics approach $(23,365,022$ GBP). Figure 2c also indicates that the non-inferior solutions obtained using the $\varepsilon$-constraint approach that gives values of the total energy consumption and the total $\mathrm{CO}_{2}$ emissions less than those of the non-inferior solutions obtained using the LPmetrics approach. As an example, it indicates that the minimum total energy consumption by the manufacturing system under solution 1 using the $\varepsilon$-constraint approach is $2,842,852 \mathrm{kWh}$ which is less than the minimum total energy consumption under the LP-metrics approach $(3,335,765 \mathrm{kWh})$ and the minimum total $\mathrm{CO}_{2}$ emissions released from the manufacturing system and the transportation vehicles, under the $\varepsilon$-constraint approach is $17.9 \times 10^{9} \mathrm{~kg}$ which is less than the minimum $\mathrm{CO}_{2}$ emissions released from the manufacturing system and the transportation vehicles, under the LP-metrics approach $\left(18.2 \times 10^{9} \mathrm{~kg}\right)$. 


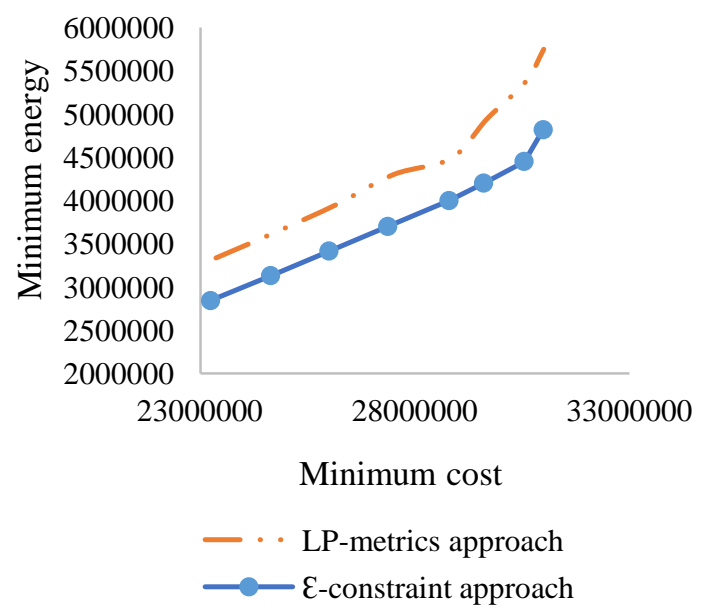

(a)

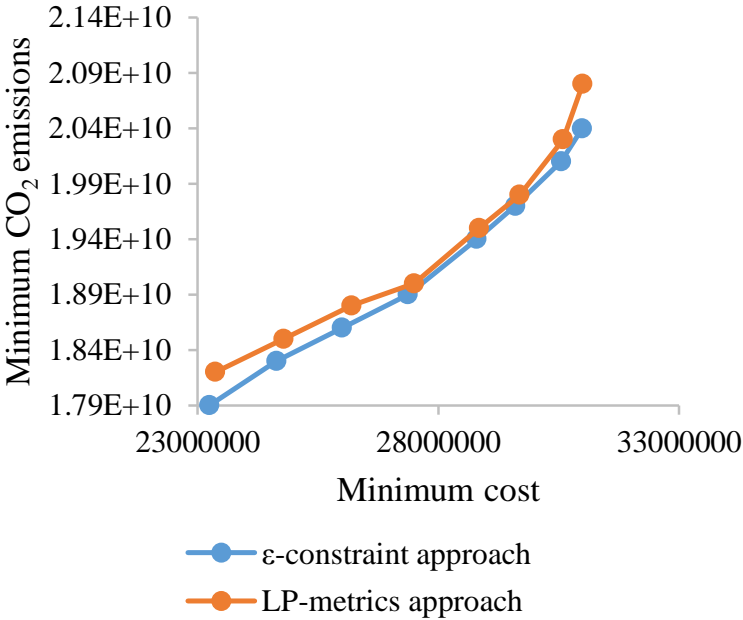

(b)

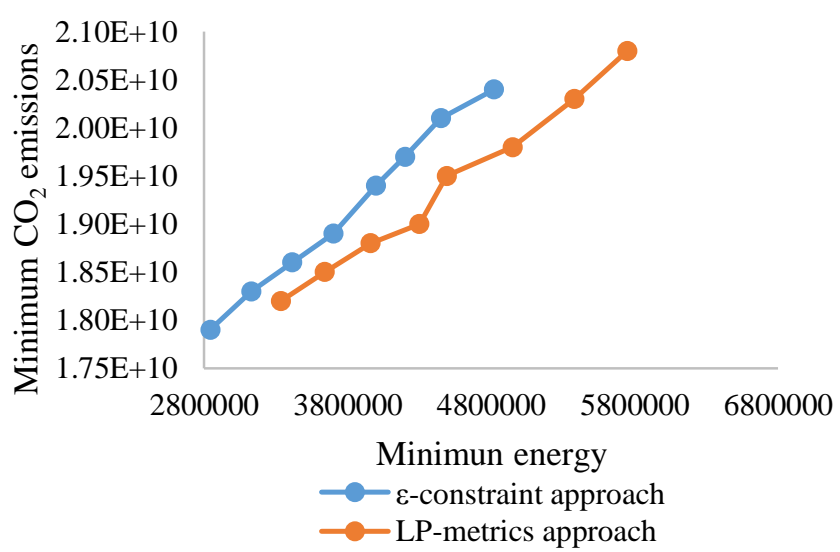

(c)

Figure 2. Comparative solutions obtained using the $\varepsilon$-constraint approach and the LP-metrics approach, respectively

Figures 3a, 3b, 3c, 3d, 3e and 3f show a comparison among potential groups in numbers of machines, air conditioning units and lighting bulbs that should be established in the manufacturing system based on solution 1 using the $\varepsilon$-constraint approach and the LP-metrics approach, respectively. The results in Figures $3 \mathrm{a}$ and $3 \mathrm{~b}$ indicate that the number of machines, air-conditioning units and lighting bulbs involved in process $j$ in supplier $s$, where $j \in\{1,2,3,4\}$ using the $\varepsilon$-constraint approach is less than the results obtained using the LP-metrics approach. For instance, as shown in process task 3, the number of machines needed under $\varepsilon$-constraint approach is 1 machine, number of air-conditioning units is 1 unit and number of lighting bulbs are 15 bulbs while the number of machines needed to be established under LP-metrics approach are 2 machines, number of airconditioning units are 1 units and number of lighting bulbs are 30 bulbs. The results in Figures $3 \mathrm{c}$ and $3 \mathrm{~d}$ indicate that the number of machines, air-conditioning units and lighting bulbs involved in process $i$ in factory $f$, where $i \in\{1,2,3,4,5,6,7,8\}$ using the $\varepsilon$-constraint approach is less than the results obtained using 
the LP-metrics approach. They indicate that the number of machines needed decreased for process task 3 from 4 to 3 and in process task 5 and 6 from 14 to 13 , i.e., from $(4,45,4,5,14,14,60,4)$ to $(4,40,3,5,13,13,60,4)$; number of air-conditioning units needed decreased for process task 2 from 23 to 20, i.e., from (2, 23, 2, 3, 7, 7, $30,2)$ to $(2,20,2,3,7,7,30,2)$ and the number of bulbs needed decreases for process task 2 from 675 to 600 , process task 3 from 60 to 45, and process task 5 and 6 from 210 to 195, i.e. from $(60,675,60,75,210,210,900$, $60)$ to $(60,600,45,75,195,195,900,60)$. Figures $3 \mathrm{e}$ and $3 \mathrm{f}$ indicate that the numbers of air conditioning units and lighting bulbs that need to be installed in warehouse $w$ using the $\varepsilon$-constraint approach is the same number as using the LP-metrics approach, which is $(832,1664)$. Arguably, the two approaches performed well in generating the non-inferior solutions, but the solutions obtained by using the $\varepsilon$-constraint approach are more stable compared to the solutions obtained by using LP-metrics approach.

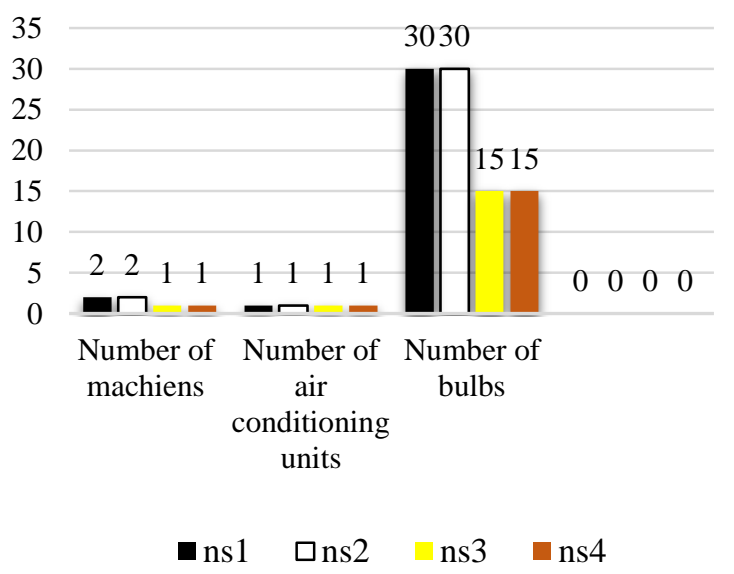

Solution 1 in supplier $s$ using $\mathcal{E}$ - constraint approach

(a)

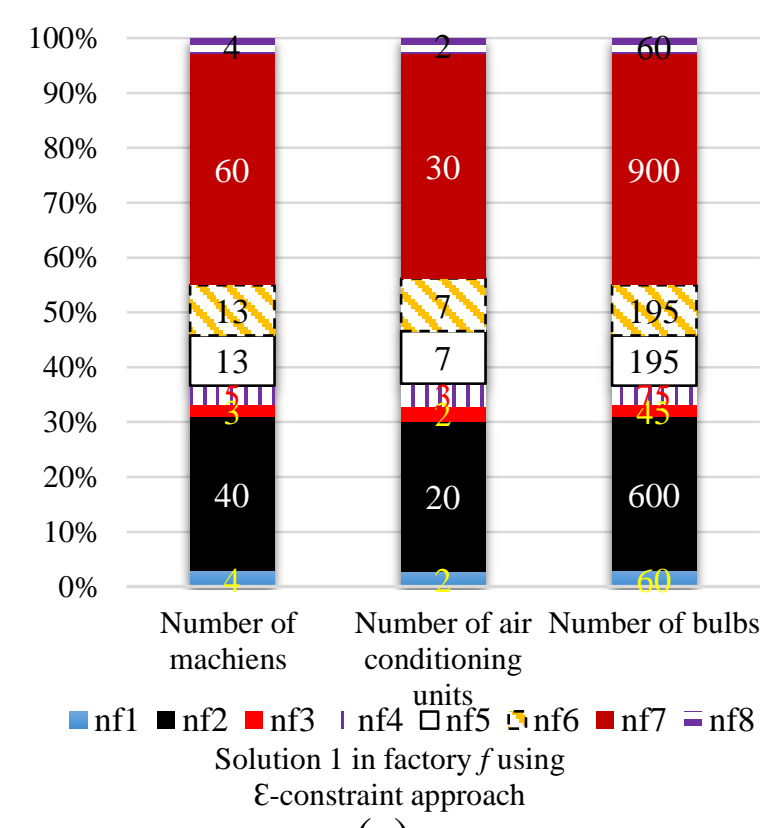

(c)

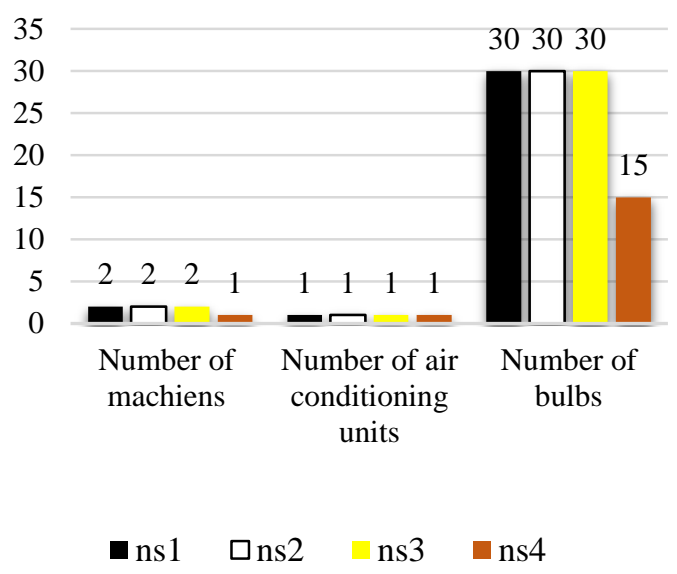

Solution 1 in supplier $s$ using LP-metrics approach

(b)

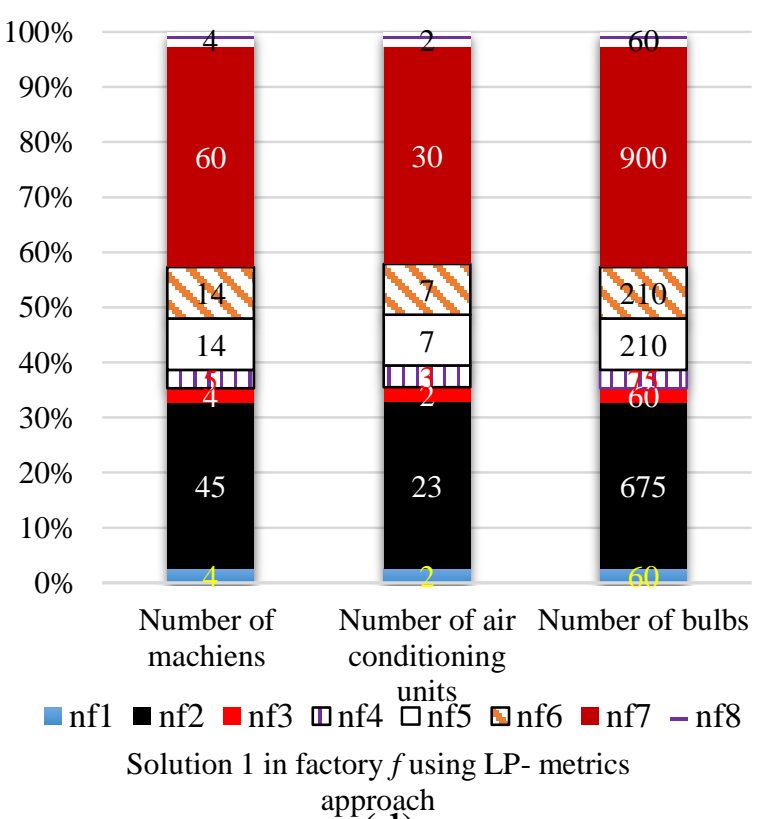

(d) 


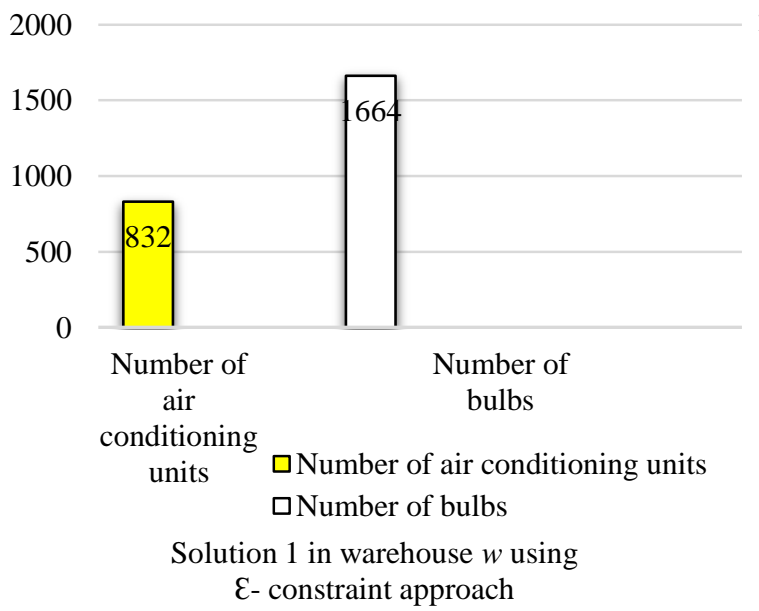

(e)

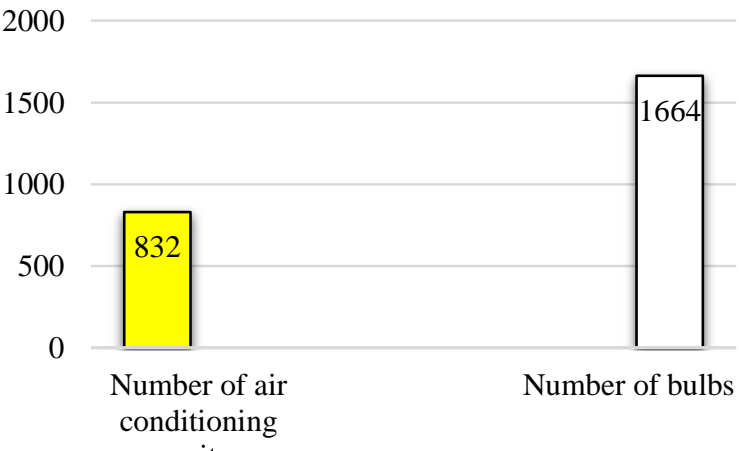

units $\quad$ Number of air conditioning units

$\square$ Number of bulbs

Solution 1 in warehouse $w$ using LP-metrics approach

(f)

Figure 3. Comparison between potential groups in numbers of machines, air conditioning units and lighting bulbs obtained by using the $\varepsilon$-constraint approach and the LP-metrics approach

In practice, based on the obtained solutions using the two optimization approaches, one of these solutions needs to be selected based on preferences of decision makers. Alternatively, it can be selected using the Max-Min approach. With the Max-Min approach (assuming $\vartheta_{\Lambda_{1}}^{r e f}=0, \vartheta_{\Lambda_{2}}^{r e f}=0.5$ and $\vartheta_{\Lambda_{3}}^{r e f}=0.5$ ), solution 1, which is obtained using the $\varepsilon$-constraint approach, is determined as the best solution as it has the minimal distance in value of 3.45 to the ideal solution. Table 10 shows the optimal solutions in quantity of material flows (i) among the machines involved in process task $j$ in supplier $s$ (ii) from supplier $s$ to factory $f$ (iii) among the machines involved in process task $i$ in factory $f$ and (iv) from factory $f$ to warehouse $w$. For instance, based on solution 4 , the optimal decisions in quantity of material flows through the machines involved in process task $(1,2,3,4)$ in supplier $s$ are $980000 \mathrm{~kg}, 978040 \mathrm{~kg}, 976084 \mathrm{~kg}, 937040 \mathrm{~kg}, 937040 \mathrm{~kg}$ which are processed through the machines involved in process task $(1,2,3,4,5,6,7,8)$ in factory $f$ before being shipped as $831540 \mathrm{~kg}$ to warehouse $w$ for storing the final products.

Table 10. The optimal quantity of material flow for the sustainable manufacturing system design

\begin{tabular}{|c|c|c|c|c|c|c|c|c|c|}
\hline \multicolumn{10}{|c|}{ Supplier $s$} \\
\hline \multirow[t]{2}{*}{$\begin{array}{l}\text { Solution } \\
\text { number }\end{array}$} & \multicolumn{4}{|c|}{$q_{s_{j}}^{r}$ where $j \in\{1,2,3,4\}$} & \multirow[t]{2}{*}{$q_{s f}^{r}$} & - & \multirow{2}{*}{-} & \multirow[b]{2}{*}{ - } & \multirow[t]{2}{*}{ - } \\
\hline & $q_{s 1}$ & $q_{s 2}$ & $q_{s 3}$ & $q_{s 4}$ & & - & & & \\
\hline 1 & 1000000 & 980000 & 978040 & 976084 & 937040 & - & - & - & \\
\hline 2 & 1020000 & 1002000 & 996100 & 994084 & 955150 & - & - & - & - \\
\hline 3 & 1045000 & 1027000 & 1009000 & 991100 & 973050 & - & - & - & - \\
\hline 4 & 1066000 & 1048000 & 1033000 & 1015000 & 997040 & - & - & - & - \\
\hline 5 & 1083000 & 1065000 & 1047050 & 1029100 & 1014100 & - & - & - & - \\
\hline 6 & 1100000 & 1067000 & 1045660 & 1043568 & 887033 & - & - & - & - \\
\hline 7 & 1120000 & 1086400 & 1053808 & 1022193 & 991527 & - & - & - & - \\
\hline 8 & 1145000 & 1110650 & 1077330 & 1045010 & 1013660 & - & - & - & - \\
\hline \multicolumn{9}{|c|}{ Factory $f$} & $\begin{array}{l}\text { Warehouse } \\
w\end{array}$ \\
\hline \multirow[t]{2}{*}{$\begin{array}{c}\text { Solution } \\
\text { number }\end{array}$} & \multicolumn{8}{|c|}{$q_{f_{i}}^{r}$ where $i \in\{1,2,3,4,5,6,7,8\}$} & \multirow{2}{*}{$q_{f w}^{m p}$} \\
\hline & $q_{f 1}$ & $q_{f 2}$ & $q_{f 3}$ & $q_{f 4}$ & $q_{f 5}$ & $q_{f 6}$ & $q_{f 7}$ & $q_{f 8}$ & \\
\hline 1 & 937040 & 918299 & 889824 & 868344 & 850660 & 840467 & 835940 & 831540 & $\begin{array}{l}7483860 \\
\text { Sacks }\end{array}$ \\
\hline 2 & 955150 & 928300 & 904824 & 883344 & 865660 & 855467 & 850940 & 846540 & 7618860 \\
\hline
\end{tabular}




\begin{tabular}{|l|l|l|l|l|l|l|l|l|l|}
\hline & & & & & & & & & Sacks \\
\hline 3 & 973050 & 940200 & 919700 & 898400 & 883660 & 870500 & 868940 & 864499 & $\begin{array}{l}7780491 \\
\text { Sacks }\end{array}$ \\
\hline 4 & 997040 & 955100 & 934824 & 919344 & 901660 & 888399 & 886950 & 880550 & $\begin{array}{l}7924950 \\
\text { Sacks }\end{array}$ \\
\hline 5 & 1014100 & 968188 & 952824 & 931344 & 916660 & 906467 & 904940 & 880555 & $\begin{array}{l}7924995 \\
\text { Sacks }\end{array}$ \\
\hline 6 & 887033 & 869292 & 834520 & 822002 & 813782 & 797507 & 795114 & 787163 & $\begin{array}{l}7084471 \\
\text { Sacks }\end{array}$ \\
\hline 7 & 991528 & 971697 & 952263 & 933218 & 914553 & 896262 & 878337 & 860770 & $\begin{array}{l}7746936 \\
\text { Sacks }\end{array}$ \\
\hline 8 & 1013660 & 993386 & 973519 & 954048 & 934967 & 916268 & 897942 & 879984 & $\begin{array}{l}7919857 \\
\text { Sacks }\end{array}$ \\
\hline
\end{tabular}

Table 11 shows the result of solution 1 in terms of numbers of machines, air conditioning units, lighting bulbs and the quantity of materials that need to be involved in the design of the sustainable manufacturing system. Figure 4 shows the optimal design of the sustainable manufacturing system based on solution 1, which was obtained with $\varepsilon_{1}=23,239,639$ and $\varepsilon_{2}=17.9 \times 10^{9}$ that yields the optimal total cost of 23,239,639 GBP, the optimal total amount of energy consumption of $2,842,852 \mathrm{kWh}$ and the optimal total amount of $\mathrm{CO}_{2}$ of $17.9 \times 10^{9} \mathrm{~kg}$

Table 10. The optimal solution for a sustainable manufacturing system design

\begin{tabular}{|c|c|c|c|c|}
\hline \multicolumn{5}{|c|}{ The optimal solution for supplier $s$} \\
\hline $\begin{array}{c}\text { Process } \\
\text { number } \\
j\end{array}$ & $\begin{array}{l}\text { Number of machines } \\
\text { involved in process } j \\
\qquad n_{s_{j}}^{\text {machin }} \\
\text { (units) }\end{array}$ & $\begin{array}{c}\text { Number of } \\
\text { air conditioning } \\
\text { units involved } \\
\text { in process } j \\
n_{s}^{\text {cond }} \\
\text { (units) }\end{array}$ & $\begin{array}{c}\text { Number of } \\
\text { bulbs } \\
\text { involved in } \\
\text { process } j \\
b u l b \\
n_{S} \\
{ }_{j} \\
\text { (units) }\end{array}$ & $\begin{array}{l}\text { Quantity of } \\
\text { materials } \\
\text { involved in } \\
\text { process } j \\
q_{s} \\
\quad(\mathrm{~kg})\end{array}$ \\
\hline 1 & 2 & 1 & 30 & 980000 \\
\hline 2 & 2 & 1 & 30 & 978040 \\
\hline 3 & 1 & 1 & 15 & 976084 \\
\hline 4 & 1 & 1 & 15 & 937040 \\
\hline \multicolumn{5}{|c|}{ The optimal solution for factory $f$} \\
\hline $\begin{array}{c}\text { Process } \\
\text { number } \\
i\end{array}$ & $\begin{array}{l}\text { Number of machines } \\
\text { involved in process } i \\
n_{f_{i}}^{\text {machin }} \\
\text { (units) }\end{array}$ & $\begin{array}{c}\text { Number of } \\
\text { air conditioning } \\
\text { units involved } \\
\text { in process } i \\
n_{\text {cond }} \\
f_{i} \\
\text { (units) }\end{array}$ & $\begin{array}{l}\text { Number of } \\
\text { bulbs } \\
\text { involved in } \\
\text { process } i \\
b u l b \\
n_{f_{i}} \\
\text { (units) }\end{array}$ & $\begin{array}{l}\text { Quantity of } \\
\text { materials } \\
\text { involved in } \\
\text { process } i \\
{ }^{q} f_{i} \\
\quad(\mathrm{~kg})\end{array}$ \\
\hline 1 & 4 & 2 & 60 & 937040 \\
\hline 2 & 40 & 20 & 600 & 918299 \\
\hline 3 & 3 & 2 & 45 & 889824 \\
\hline 4 & 5 & 3 & 75 & 868344 \\
\hline 5 & 13 & 7 & 195 & 850660 \\
\hline 6 & 13 & 7 & 195 & 840467 \\
\hline 7 & 60 & 30 & 900 & 835940 \\
\hline 8 & 4 & 2 & 60 & 831540 \\
\hline \multicolumn{5}{|c|}{ The optimal solution for warehouse $w$} \\
\hline $\begin{array}{l}\text { Process } \\
\text { number }\end{array}$ & $\begin{array}{l}\text { Number of machines } \\
\text { involved in process }\end{array}$ & $\begin{array}{c}\text { Number of } \\
\text { air conditioning } \\
\text { units } \\
n_{w}^{c o n d} \\
\text { (units) }\end{array}$ & $\begin{array}{l}\text { Number of } \\
\text { bulbs } \\
n_{w}^{b u l b} \\
\text { (units) }\end{array}$ & $\begin{array}{c}\text { Number of } \\
\text { manufacturing } \\
\text { products } \\
{ }^{q} \mathrm{fw} \\
\text { (units) }\end{array}$ \\
\hline- & - & 832 & 1663 & $7,483,860$ sacks \\
\hline
\end{tabular}




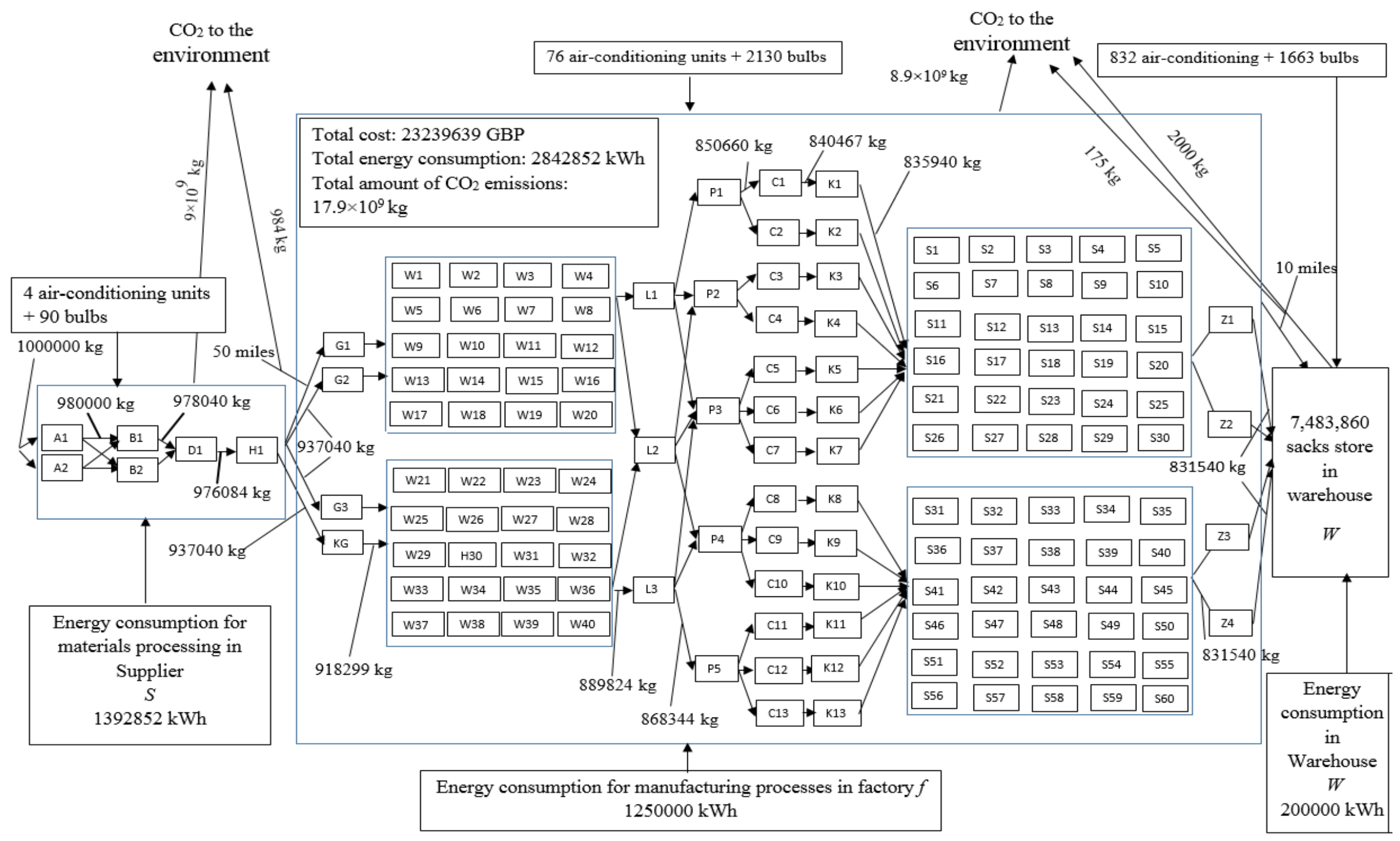

Figure 4. An optimal sustainable manufacturing system design 


\section{Conclusion and discussion}

In a traditional manufacturing system design, engineers used to focus on indicators of system performance in terms of output, capacity, efficiency and other production related parameters; environmental considerations are often overlooked as part of manufacturing systems analysis, design and performance evaluation. This paper presents a study in developing a multi-objective optimization model used as an aid for decision-makings of a sustainable manufacturing system, which includes the facilities of supplier $s$, factory $f$ and warehouse $w$. The multi-objective model consists of three objective functions aimed at minimizing the total cost, the total energy consumption and the amount of $\mathrm{CO}_{2}$ emissions for establishing facilities and transportation vehicles within a manufacturing system. To reveal the non-inferior solutions, two approaches were investigated, these are the $\varepsilon^{-}$ constraint approach and the LP-metrics approach. The computational results are obtained and compared using the above approaches and the max-min approach was employed to determine the best solution. A real case study was used for examining the applicability of the developed mathematical model which supports manufacturing system designers to develop a sustainable manufacturing system.

Nevertheless, mathematical or analytical modelling techniques might not be sufficient if a detailed analysis is required for a complex manufacturing system as the objective function may not be expressible as an explicit function of the input parameters. In some cases, one must resort to simulation even though in principle some systems are analytically tractable; this is because some performance measures of the system have values that can be observed only by running the computer-based simulation model (Wang and Chatwin, 2005). Thus, an integrated method incorporating environmental parameters for a discrete even simulation model is recommended as part of this study, which is under the development.

Future work should focus on improving the developed model by considering a multi-period multi-objective model and formulating the end of life disposal of the products in terms of a closed loop supply chain when configuring the SMS.

\section{Acknowledgements}

The authors would like to express their gratitude to the Ministry of Education in Saudi Arabia for the financial support in this study. Also, the authors would like to thank the anonymous referees whose thorough reviews and insightful comments made a valuable contribution to this article.

\section{References}

Abdallah, T., Diabat, A., \& Simchi-Levi, D. (2010). A carbon sensitive supply chain network problem with green procurement, proceedings of the $40^{\text {th }}$ International Conference in Computers and Industrial Engineering (CIE), 1-6. IEEE.

Alçada-Almeida, L., Coutinho-Rodrigues, J., \& Current, J. (2009). A multi-objective modeling approach to locating incinerators, Socio-Economic Planning Sciences, 43, 111-120.

Amin, S. H., \& Zhang, G. (2013). A multi-objective facility location model for closed-loop supply chain network under uncertain demand and return, Applied Mathematical Modelling, 37(6), 416.

Bortolini, M., Faccio, M., Ferrari, M., Gamberi, M. and Pilati, F. (2016). Fresh Food Sustainable Distribution: Cost, Delivery Time And Carbon Footprint Three-Objective Optimization. Journal of Food Engineering, 174, 56-67.

EPA. (2008). The Lean and Environment Toolkit. U.S. Environmental Protection Agency, http://www.epa.gov/lean/toolkit/index.htm accessed June 26.

Fesanghary, M., Asadi, S., \& Geem, Z. W. (2012). Design of low-emission and energy-efficient residential buildings using a multi-objective optimization algorithm. Building and environment, 49, 245-250.

Gielen, D., \& Moriguchi, Y. (2002). $\mathrm{CO}_{2}$ in the iron and steel industry: an analysis of Japanese emission reduction potentials, Energy Policy, 30, 349-363.

Hamdy, M., Hasan, A., \& Siren, K. (2011). Applying a multi-objective optimization approach for design of lowemission cost-effective dwellings. Building and environment, 46(1), 109-123. 
Harris, I., Mumford, C.L. and Naim, M.M. (2014). A hybrid multi-objective approach to capacitated facility location with flexible store allocation for green logistics modeling. Transportation Research Part E: Logistics and Transportation Review, 66, 1-22.

Heilala, J., Vatanen, S., Tonteri, H., Montonen, J., Lind, S., Johansson, B., \& Stahre, J. (2008). Simulationbased sustainable manufacturing system design, Proceedings of the 2008 Winter Simulation Conference. 1922-1930.

Hidalgo, I., Szabo, L., Ciscar, C., \& Soria, A. (2005) Technological prospects and $\mathrm{CO}_{2}$ emission trading analyses in the iron and steel industry, a global model. Energy, 30, 583-610.

Jamshidi, R., Ghomi, S. F., \& Karimi, B. (2012). Multi-objective green supply chain optimization with a new hybrid memetic algorithm using the Taguchi method, Scientia Iranica, 19(6), 1876-1886.

Jayal, A.D., Badurdeen, F., Dillon, J.r .O.W., Jawahir, I.S. (2010). Sustainable manufacturing modeling and optimization challenges at the product, pro-cess and system levels. CIRP J Manuf Sci Technol , 2, 144-52.

Jawahir, I.S., Jayal, A.D. (2011). Product and process innovation for modeling of sustainable machining processes. In: Seliger G, Khraisheh MMK, Jawahir IS, editors. Adv. Sustain. Manuf. Berlin Heidelberg: Springer, 2011, 301-7.

Koç, E., \& Kaplan, E. (2007). An investigation on energy consumption in yarn production with special reference to ring spinning, J. Fibr \& Texti in Eas. Eur, 4, 18-24.

Lai, Y.L., \& Hwang, C.L. (1992). Fuzzy mathematical programming, 1st ed., Springer: Berlin.

Li, C., Zhang, X., Zhang, S., Suzuki, K. (2009). Environmentally conscious design of chemical processes and products, multi-optimization method. Chem. Eng. Res. Des. 87, 233-243.

Lind, S., Krassi, B., Johansson, B., Viitaniemi, J., Heilala, J., Stahre, J., ... \& Berlin, C. (2008). SIMTER: a production simulation tool for joint assessment of ergonomics, level of automation and environmental impacts. In The 18th International Conference on Flexible Automation and Intelligent Manufacturing.

Mohammed, A., Wang, Q., Alyahya, S. and Bennett, N. (2016). Design and optimization of an RFID-enabled automated warehousing system under uncertainties: a multi-criterion fuzzy programming approach. The International Journal of Advanced Manufacturing Technology.

Mohammed, A., \& Wang, Q. (2016). The fuzzy multi-objective distribution planner for a green meat supply chain. International Journal of Production Economics.

Nishant, R., Teo, T.S.H., Goh, M. (2014). Energy efficiency benefits: is technophilic optimizm justified? IEEE Trans Eng Manage, 61, 476-87.

Nujoom, R., Wang, Q., \& Bennett, N. (2016 a). An Integrated Method for Sustainable Manufacturing Systems Design, Proceedings of the $3^{\text {rd }}$ International Conferences in MATEC, vol. 70, 1-5, Istanbul, Turkey.

Nujoom, R., Mohammed, A., Wang, Q., \& Bennett, N. (2016 b). The multi-objective optimization model for a sustainable manufacturing system design. In Renewable Energy Research and Applications (ICRERA), 2016 IEEE International Conference on 1134-1140.

Nurjanni, K. P., Carvalho, M. S., \& da Costa, L. A. A. F. (2014). Green supply chain design with multiobjective optimization, Proceedings of the 2014 International Conference on Industrial Engineering and Operations Management Bali, Indonesia, 7-9.

Pagell, M., Yang, C.L., Krumwiede, D.W., \& Sheu, C. (2004). Does the competitive environment influence the efficacy of investment in environmental management?, Journal of Supply Chain Management, 40(3), 3039.

Paksoy, T., Pehlivan, N.Y. and Özceylan, E. (2012). Fuzzy multi objective optimization of green supply chain network with risk management of included environmental hazards. Human and Ecological Risk Assessment (SCI), 18 (5), 1121-1152.

Pinto-Varela, T., Barbosa-Póvoa, A. P. F., \& Novais, A. Q. (2011). Bi-objective optimization approach to the design and planning of supply chains: economic versus environmental performances. Computers \& Chemical Engineering, 35(8), 1454-1468.

Pishvaee, M. S \& Razmi, J. (2012). Environmental supply chain network design using multi-objective fuzzy mathematical programming. Applied Mathematical Modelling 36 (8), 3433-3446.

Pusavec, F., Krajnik, P., Kopac, J. (2010). Transitioning to sustainable production-PartI: Application on machining technologies. J Clean Prod, 18, 174-84.

Rodger, J. A., \& George, J. A. (2017). Triple bottom line accounting for optimizing natural gas sustainability: A statistical linear programming fuzzy ILOWA optimized sustainment model approach to reducing supply 
chain global cybersecurity vulnerability through information and communications technology. Journal of Cleaner Production, 142, 1931-1949.

Sahar, V., Arijit B. and Byrne, P.J. (2014). A Case Analysis Of A Sustainable Food Supply Chain Distribution System-A Multi-Objective Approach. International Journal of Production Economics, 152, 71-87.

Sharafi, M., \& ELMekkawy, T. Y. (2014). Multi-objective optimal design of hybrid renewable energy systems using PSO-simulation based approach. Renewable Energy, 68, 67-79.

Shaw, K., Shankar, R., Yadav, S. S., \& Thakur, L. S. (2012). Supplier selection using fuzzy AHP and fuzzy multi-objective linear programming for developing low carbon supply chain, Expert systems with applications, 39(9), 8182-8192.

Taghdisian, H., Pishvaie, M. R., \& Farhadi, F. (2015). Multi-objective optimization approach for green design of methanol plant based on CO 2-efficeincy indicator. Journal of Cleaner Production, 103, 640-650.

Wang, C., Larsson, M., Ryman, C., Grip, C. E., Wikström, J. O., Johnsson, A., \& Engdahl, J. (2008). A model on $\mathrm{CO}_{2}$ emission reduction in integrated steelmaking by optimization methods, International journal of energy research, 32(12), 1092-1106.

Wang, F., Lai, X., \& Shi, N. (2011). A multi-objective optimization for green supply chain network design, Decision Support Systems, 51, 262-269.

Wang, Q., Lassalle, S., Mileham, A. R., \& Owen, G. W. (2009). Analysis of a linear walking worker line using a combination of computer simulation and mathematical modeling approaches. Journal of Manufacturing Systems, 28(2-3), 64-70.

Wang, Q., \& Chatwin, C.R. (2005). Key issues and developments in modelling and simulation-based methodologies for manufacturing systems analysis, design and performance evaluation. International Journal of Advanced Manufacturing Technology, 25 (11-12), 1254-1265.

Zhou, C. C., Yin, G. F., \& Hu, X. B. (2009). Multi-objective optimization of material selection for sustainable products: artificial neural networks and genetic algorithm approach. Materials \& Design, 30(4), 1209-1215. 